\title{
Tourette Syndrome Treatment Updates: a Review and Discussion of the Current and Upcoming Literature
}

\author{
Jessica Frey $^{1}$ (D) . Irene A. Malaty ${ }^{1}$ \\ Accepted: 27 December 2021 / Published online: 2 February 2022 \\ (c) The Author(s), under exclusive licence to Springer Science+Business Media, LLC, part of Springer Nature 2022
}

\begin{abstract}
Purpose of Review This study aims to examine the treatments currently available for Tourette syndrome (TS) and to discuss evolving therapies, spanning behavioral, pharmacologic, complementary and alternative medicine, and neuromodulation approaches.

Recent Findings Behavioral therapies have undergone several modifications to improve accessibility, including transitioning to a virtual format which is particularly important in the current pandemic. There are several recent or ongoing pharmacologic studies that have shown promise including the selective D1 receptor antagonist ecopipam and various cannabinoid compounds. Adaptive DBS may enable the physiologic markers of tics to determine stimulation parameters and improve tic outcomes related to neuromodulation.

Summary In recent years, there has been a wealth of research across multiple treatment domains in the TS field. This review highlights exciting and new potential options for the future treatment of patients with TS.
\end{abstract}

Keywords Tourette syndrome $\cdot$ Tics $\cdot$ CBIT $\cdot$ Pharmacotherapy $\cdot$ Neuromodulation $\cdot$ Deep brain stimulation

\section{Introduction}

Tourette syndrome (TS) is a childhood-onset disorder in which multiple motor tics and at least one phonic tic occur, lasting beyond a year and typically fluctuating over time. Although in many cases tics can be mild and nonbothersome, in others, tics can cause physical discomfort, academic and professional detriment, and social disability. Tics in TS may be associated with a number of comorbidities, including anxiety, attention deficit hyperactivity disorder (ADHD), and obsessive-compulsive disorder (OCD). Genetic factors drive some portion of risk, and hyperactivity in dopamine circuitry seems to play a pivotal role in the pathophysiology. Management begins with education about the nature of tics. When tics impair quality of life, there are many established and evolving treatment options that may

This article is part of the Topical Collection on Movement Disorders

Irene A. Malaty

irene.malaty@neurology.ufl.edu

1 Department of Neurology, Fixel Institute for Neurological Diseases, University of Florida, Gainesville, FL, USA be considered. This review will discuss treatment updates for TS, including behavioral and other non-pharmacologic interventions, pharmacologic strategies, and neuromodulatory approaches.

\section{Non-pharmacologic Interventions}

Although pharmacotherapy plays a major role in the treatment of TS, medication side effects are common and may accumulate over time. For this reason, more conservative approaches are often considered first-line, including psychoeducation, behavioral interventions, and biofeedback.

\section{Psychoeducation and Supportive Therapy (PST)}

Psychoeducation and supportive therapy (PST) can help to mitigate misunderstandings of TS, reduce perceived stigmas, and provide age-appropriate explanations for TS and associated comorbidities [1]. One meta-analysis found that PST improves knowledge and misconceptions regarding TS [2]. However, a diagnostic label in isolation may lead to negative expectations of certain behaviors or even exacerbate symptoms [2]. Therefore, it is important that information is used 
to increase awareness and promote acceptance [2]. There is evidence for further reduction in tics when PST is added to pharmacotherapy, relative to pharmacotherapy alone [3]. PST has expanded to incorporate video footage [2] and telepsychoeducation strategies effectively [4].

Reliable information is critical to supporting well-being with tics. Virtual communication and social media use skyrocketed in the face of the COVID-19 pandemic, and individuals, particularly adolescents, increasingly turn to the Internet and social media for healthcare information $[5,6]$. The increased consumption of information about TS from public sources with variable accuracy, combined with social isolation and need for connection, may have contributed to increased frequency of explosive onset functional tic-like behaviors [7]. Social media "influencers" have posted videos with very particular and extreme manifestations, and online communities have encouraged sharing tics and rating their severity. Although online support groups offer many positives with regard to acceptance, community, and information sharing, they may unintentionally propagate inaccurate ideas about tics and influence tic expression given the suggestibility of tics [8]. Therefore, it is equally important to educate patients about sources where reliable information about TS is available.

Multiple treatment guidelines recommend clinicians use psychoeducation to help educate patients, teachers, and peers about the natural history of TS $[9 \bullet \bullet, 10 \bullet \bullet, 11]$. Strategies to disseminate PST have recently been outlined in a guide by $\mathrm{Wu}$ and McGuire (2018) [12]. Combining education on an individual level with dissemination of resources that can aide educators or family members, such as those available through Tourette syndrome-focused national organizations, is advisable.

\section{Behavioral Interventions}

Behavioral interventions have the advantage of being effective at reducing tics without significant adverse effects and therefore are the first-line treatment according to several treatment guidelines $[9 \bullet \bullet, 10,11,13 \bullet \bullet, 14 \bullet \bullet]$. At least one study has demonstrated that behavioral interventions are comparable to pharmacotherapy at reducing tics [15]. Exposure and response prevention (ERP) exposes patients to the unpleasant sensation associated with a premonitory urge, simultaneously teaching habituation to the urge and how to prevent the tic from occurring [16]. Habit reversal therapy (HRT), which involves awareness training, competing response practice, and habit control motivation and generalization training, was one of the earliest behavioral interventions successfully used to reduce tics [17]. There is evidence that both of these interventions are effective at reducing tics [18-25]. Since then, HRT has been expanded into comprehensive behavioral intervention for tics (CBIT), which includes psychoeducation, relaxation training, behavioral rewards, and function-based interventions [16]. Several critiques of CBIT, including that it is only useful for patients with mild tics, that it requires considerable effort for patients, that the tic improvements are modest and not sustained over time, and that CBIT may result in tic substitution or worsening, have been disproven [26, 27]. Although CBIT has not been shown to improve psychiatric comorbidities[24, 28], CBIT has repeatedly been shown to reduce tic frequency and severity with long-term improvement [29-32].

\section{Modifications of Existing Behavioral Interventions}

The original CBIT study was geared toward pediatric TS patients aged 9-17 years [30]. Since then, CBIT has undergone a variety of modifications (Table 1). CBIT has been adapted via "The Opposite Game" for children as young as 5-8 years of age [33]. An educational HRT-training DVD has been incorporated for families at home in parallel to in-person CBIT [34]. CBIT has been expanded to group settings [35-38]. Cognitive psychophysiological approaches to address both tics and cognitive issues have been created [39, 40]. The typical 8 sessions delivered over 10 weeks has been reduced to 4 sessions delivered over 3 months [41] and, in some cases, condensed into a single week [42, 43]. These CBIT modifications have all been shown to reduce tics as effectively as traditional CBIT and improve accessibility, especially in communities in which there is a shortage of CBIT-trained providers.

\section{Virtual or Tele-behavioral Interventions}

Flexible methods of CBIT delivery have become especially important during the COVID-19 pandemic, which fueled rapid widespread implementation of telehealth. When delivered virtually, there are similar reductions in tic severity comparable to in-person behavioral interventions[44-46], and subjects found telehealth delivery to be an acceptable format [44]. A virtual, self-guided format provided by the website TicHelper.com is available for independent patient use [47]. An alternative virtual platform called TicTrainer incorporates ERP-like strategies via a self-guided website [48], and additional virtual CBIT programs have recently been proposed [49, 50]. However, further work is needed to establish the comparative efficacy of these modalities.

\section{Biofeedback}

Based on the observation that autonomic changes impact tic expression and frequency [51], biofeedback has been attempted to exert voluntary control over symptoms by providing feedback through psychological or physiological means [52]. Studies using electrodermal biofeedback have 


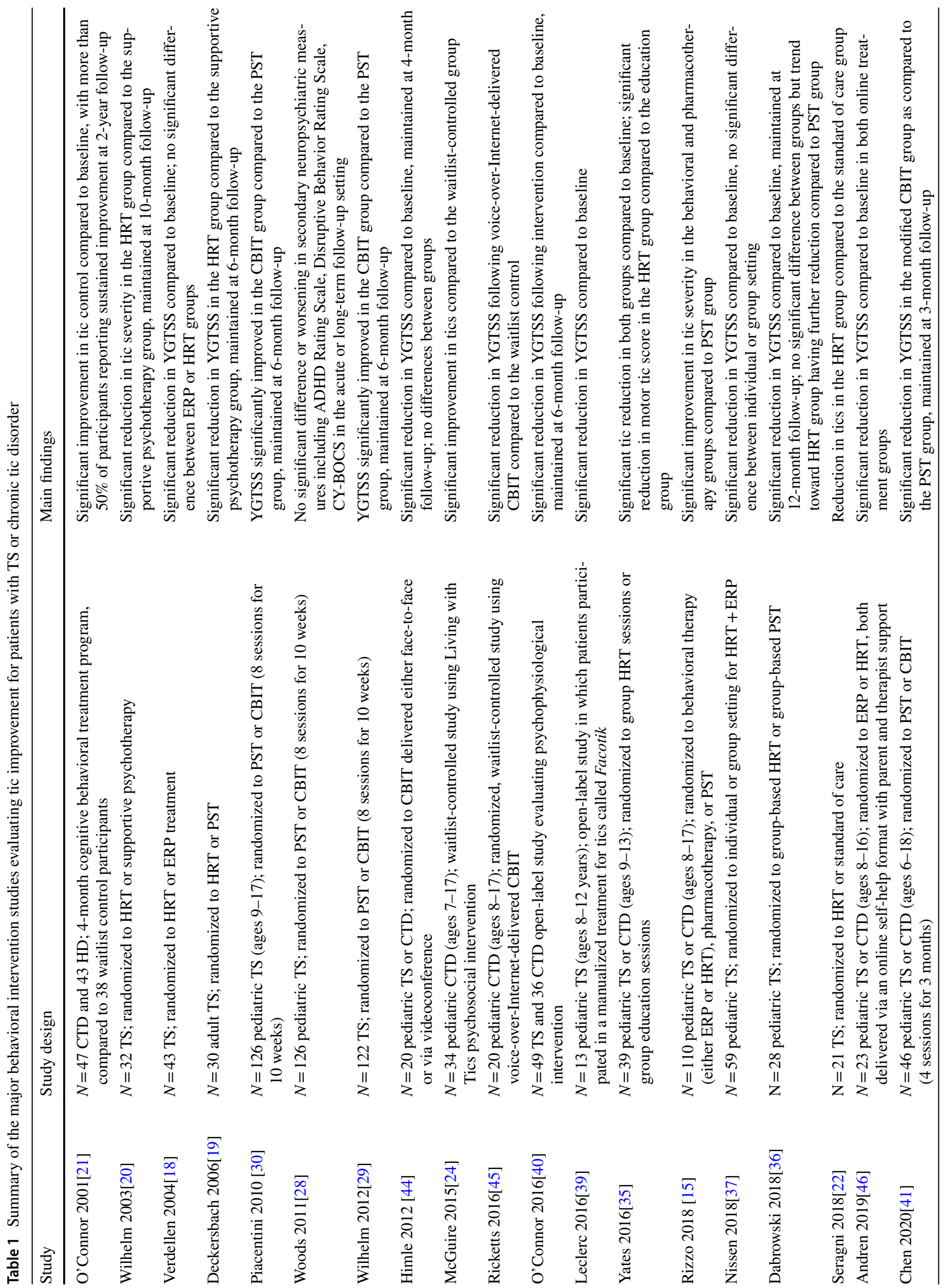




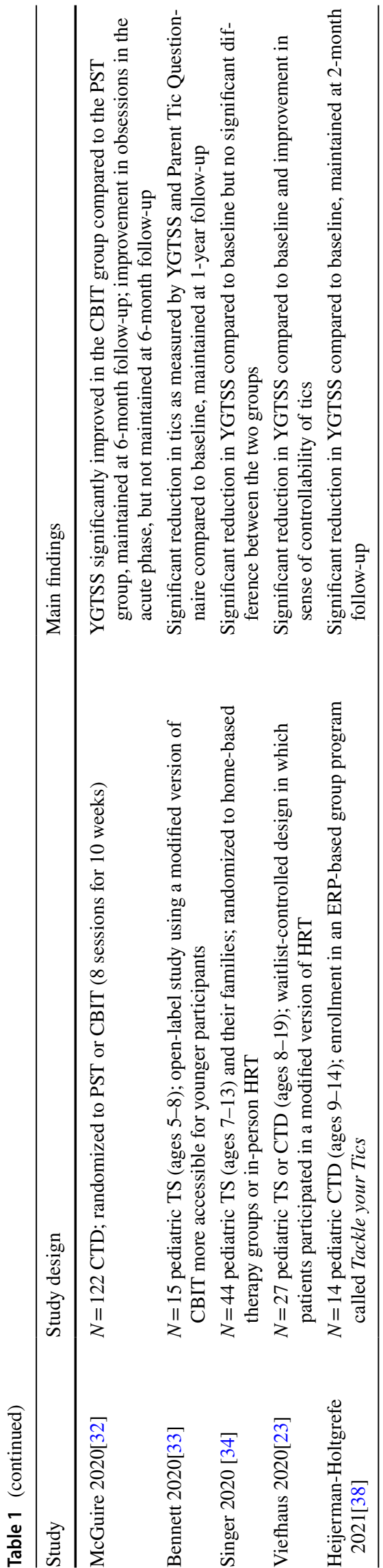

been mixed [52,53], but a recent fMRI neurofeedback study was able to demonstrate significant reduction in tics compared to sham neurofeedback [54].

In summary, behavioral therapies are generally lowrisk. When accessible, they are recommended as first-line or adjunctive treatment components when tic severity does not call for urgent pharmacologic intervention or when individual preference or characteristics do not make them unsuitable.

\section{Pharmacologic Interventions}

In spite of the widespread use of pharmacotherapy for the treatment of TS, there is a surprising lack of large, wellcontrolled studies for medication efficacy in TS [55]. Medications should be considered in patients if more conservative treatments such as behavioral interventions are ineffective or if the tics are severe [56•]. Although there are a wide variety of medication options for TS, only 3 medications are currently FDA-approved for use in TS: haloperidol ( $>3$ years old), pimozide ( $>12$ years old), and aripiprazole (ages 6-18 years old) [55]. In clinical practice, choosing which medication to use depends on tic severity, comorbidities, and potential adverse effects.

\section{Alpha-2-adrenergic Agonists}

Due to their relatively safer side effect profile, the medications that are most often recommended as first-line pharmacotherapy are alpha-2-adrengergic agonists, which may work to suppress the sympathetic nervous system [57•]. Although early studies of the effectiveness of clonidine were mixed [58], clonidine has been shown to be more effective than placebo at reducing tics [59] and additionally helps improve tics in patients with comorbid TS and ADHD [60]. The clonidine adhesive patch has additionally been shown to be safe and effective for TS management [61-63] and is comparable to haloperidol [64-66]. Guanfacine has had mixed results with some studies demonstrating safety and efficacy $[67,68]$, but others not demonstrating significant tic reduction $[69,70]$. Therefore, clonidine is recommended with moderate confidence in the evidence, whereas guanfa-

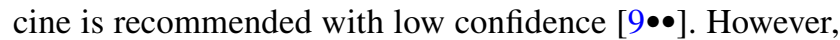
guanfacine may be less sedating because of selectivity for alpha-2 receptors and therefore is often chosen over clonidine in clinical practice [56•]. To date, guanfacine and clonidine have not been directly compared.

\section{GABAergic Medications and Anticonvulsants}

Given that dysfunctional GABA pathways may contribute to the underlying etiology of TS, medications that act on 
GABA receptors or influence GABA concentrations have been explored for use in the treatment of TS [71]. Topiramate, a broad-spectrum antiepileptic, has been studied in a double-blind, placebo-controlled study with significantly reduced tics compared to placebo [72], and a retrospective study found similar results [73]. Side effects include paresthesias, cognitive slowing, and decrease in appetite leading to weight loss, as well as increased risk of glaucoma and kidney stones [57•]. Levetiracetam had mixed results in placebo-controlled trials: one small study with improvement [74] and two others without [75, 76]. Clonazepam and baclofen have been reported in case reports and case series or open-label reports but are without RCTs demonstrating tic reduction [57•, 77•]. Baclofen showed improvement in impairment scores but not tics in one small RCT [78]. Based on a meta-analysis of treatments for TS, topiramate was found to possibly have some benefit compared to placebo, whereas there is insufficient evidence to determine if levetiracetam, clonazepam, or baclofen would have any more benefit compared to placebo [ $9 \bullet \bullet$. In practice, topiramate can be useful when weight gain from neuroleptics has occurred or is undesirable. Benzodiazepines may have a limited role when comorbid anxiety is prominent, weighing benefit against risk of dependence, and baclofen may be considered if severe muscle pain or tension is present.

\section{Dopamine Receptor Blocking Agents (Neuroleptics)}

Due to potential significant side effects, dopamine receptor blocking agents are generally used as second-line agents [79]. A recent meta-analysis summarized most common side effects: increased risk of weight gain with risperidone and aripiprazole; elevated prolactin levels with pimozide, haloperidol, and metoclopramide; increased risk of sedation with risperidone, aripiprazole, tiapride, clonidine, and guanfacine; and increased risk of extrapyramidal symptoms or parkinsonism with pimozide, haloperidol, and risperidone [13••]. In addition, serious cardiac side effects such as QTC prolongation can occur, especially in pimozide and ziprasidone $[56 \bullet, 80]$. In practice, these potential side effects may occur with any of the medications in this class.

Although haloperidol was one of the earliest dopamine blocking agents to demonstrate efficacy for the treatment of TS, follow-up studies have shown that it has more serious side effects and is inferior to other agents [57•]. Thus, haloperidol is typically used only after other medications have failed. Ziprasidone, fluphenazine, olanzapine, and quetiapine are antipsychotics that are sometimes recommended by experts in the field; however, evidence to support their use in TS is limited [77•]. Studies have demonstrated that both pimozide and risperidone lead to significant tic reduction in comparison to placebo as well as in comparison to several alternative dopamine blocking agents [57•, 77•].
Aripiprazole is an atypical neuroleptic with partial agonist activity on D2 dopamine receptors, as well as serotonergic effects. Two meta-analyses found that across 17 RCTs, aripiprazole was well-tolerated, with significantly less side effects and similar efficacy compared to placebo or other agents [81, 82]. A recent RCT compared aripiprazole to intravenous valproic acid and determined that both treatments led to similar significant reduction in tics, though the intravenous valproic acid group responded to treatment faster [83].

Benzamides such as tiapride, sulpiride, and amisulpiride are D2-blocking agents that are commonly used to treat TS outside of the USA [77•]. In contrast to other dopamine receptor blocking agents, benzamides have fewer extrapyramidal side effects [77•, 84]. Most evidence for benzamides comes from remote open-label studies or case reports [77•]. There have been no recent studies assessing the efficacy of these medications.

A recent meta-analysis found that there is moderate confidence that haloperidol, risperidone, aripiprazole, and tiapride would lead to tic reduction compared to placebo, whereas pimozide and ziprasidone were only possibly more likely to receive benefit in tic severity compared to placebo $[13 \bullet \bullet]$.

Ecopipam is a first-in-class drug that has selective D1 receptor antagonism. An open-label study demonstrated that ecopipam was safe and led to significant tic reduction [85], and a follow-up placebo-controlled trial demonstrated similar results [86]. A phase IIb trial called the D1 AMOND study is currently underway to test ecopipam further (NCT04007991) with a corresponding open-label extension following the randomization period (NCT04114539).

\section{VMAT2 Inhibitors}

Biogenic amines including dopamine are transported by vesicular monoamine transporter-2 (VMAT-2). VMAT2 inhibitors work by depleting dopamine pre-synaptically [56•]. In open-label studies, tetrabenazine has reduced tics [87, 88]. Deutetrabenazine is an isomer of tetrabenazine with a longer half-life and less risk of side effects [77•]. Open-label studies have demonstrated that deutetrabenazine is safe and effective for tic disorders [89]. However, the phase 2/3 ARTIST1 and phase 3 ARTIST2 trials failed to reach the primary end point of tic reduction (NCT03567291, NCT03571256). The safety and tolerability of valbenazine for tics were established in the T-Force study but placebo-controlled trials in adults (T-Forward), pediatrics at fixed doses (T-Force green), and pediatrics at optimized doses (T-Force gold), as well as open-label extension studies (T-Fusion and T-Force gold +) failed to meet the primary endpoint [90]. As a result, this class of medications is often reserved for cases that have been refractory to other classes or in whom potential side effect profiles favor avoiding other classes. 


\section{Cannabinoids}

The two main types of cannabinoids are tetrahydrocannabinol (THC) (psychoactive) and cannabidiol (CBD) (non-psychoactive) [55]. Dronabinol is a synthetic version of THC and nabiximol is part THC and part CBD [55]. Patients selfreporting tic improvement following use of cannabinoids have led to interest in studying them systematically [91]. A placebo-controlled trial of a single dose of THC led to significant reduction in tics [92] and when administered for 6 weeks led to significant improvement in subjects' perceived tic severity and quality of life as well as trends toward reduction in tic scores [93]. A Cochrane review determined that there was not enough evidence to support whether or not cannabinoids are an effective treatment for TS [94]. Side effects include dry mouth, nausea/vomiting, headache, fatigue, disorientation, and anxiety [95]. Risks that may be specific to the developing brain have not been fully explored.

A recent survey revealed that in patients who have independently used cannabinoids for TS treatment, patients tend to favor THC-rich cannabis over dronabinol or nabiximols [96]. There are currently several ongoing trials. An RCT was planned with different ratios of THC and CBD versus placebo to determine if a specific composition would have better safety and efficacy; however, the study was terminated due to slow enrollment (NCT03247244). A study comparing a THC and CBD compound in a 1:1 ratio versus an inert oil has been registered, but results are not yet available (ACTRN12618000545268). Similarly, the CANNA-TICS protocol plans to test nabiximol in comparison to placebo [97].

There have also been attempts to modify the endogenous endocannabinoid system in the treatment of TS. Lu-AG06466 (previously referred to as ABX-1431) is a selective inhibitor of monoacylglycerol lipase (MAGL), which prevents the breakdown of an endogenous ligand of the endocannabinoid system [95]. In a single-dose placebocontrolled crossover study evaluating Lu-AG06466 in 20 adult patients with TS, there was significant improvement in tic scores [98]. However, a follow-up multicenter, double-blind, randomized, placebo-controlled trial found no significant differences in tic severity between Lu-AG06466 and placebo at 8-week follow-up [99]. In addition to these studies, there are active trials evaluating palmitoylethanolamide (PEA), which is an endogenous fatty acid amide that mimics the properties of cannabinoids [95]. Furthermore, PEA may reduce the side effects associated with cannabinoids, making it an appealing compound to study in combination with traditional cannabinoids [95]. A phase 2 openlabel study evaluating dronabinol in combination with PEA (THX-110) found an averaged YGTSS reduction of 20\% compared to baseline [100]. A larger, placebo-controlled trial is currently under development (NCT03651726). In addition, the psychoactive properties of cannabinoids need to be accounted for when designing placebo-controlled trials in the future.

\section{Botulinum Toxin Injections}

Botulinum toxin inhibits acetylcholine release at the neuromuscular junction, leading to temporary relaxation of the muscle injected [77•]. There have been several case reports [101-104] and open-label studies [105-108] that demonstrated botulinum toxin led to significant reduction in tics. However, only one randomized, placebo-controlled trial has been conducted with botulinum toxin in the TS population [109], which was the only study which met the criteria for a recent Cochrane review, classifying the evidence for botulinum toxin in TS as low-quality [110]. A meta-analysis of treatments for TS has determined that onabotulinumtoxin A injections are probably more likely to reduce tic severity compared to placebo [13••]. In practice, botulinum toxin injections may be most helpful for specific focal tics such as blinking, facial movements, neck jerking, and disabling coprolalia or loud vocal tics (vocal cord injections). Risks generally relate to excessive weakness of injected or surrounding muscles, so careful dosing and expert injection are critical.

\section{Complementary Alternative Medicine (CAM) and Supplementation}

Due to the side effects associated with pharmacologic treatments, there is increasing interest in using complementary alternative medicine (CAM). A wide range of CAM modalities including meditation, vitamins, prayer, and other homeopathic regimens have been implemented, though not well-studied systematically [111].

Two recent meta-analyses reported that traditional Chinese medicine (TCM) had the potential to reduce tics relative to placebo or western medicine $[112,113 \bullet]$. Ningdong granule (NDG) is a combination of plant, animal, and placental products thought to modulate the D2 receptor pathway and has been shown to be well-tolerated and effective at reducing tics compared to placebo [77•]. Choudongning $(\mathrm{CDN})$ capsule has shown promise in several double-blind, placebo-controlled studies [113•, 114, 115]. 5-Ling granule (5-LGr) contains 11 different herbs and has shown comparable efficacy to tiapride with better tolerability [116]. Another proprietary polyherbal product called Changma Xifeng was reported to have similar efficacy as western medicine [117, 118]. In addition, a placebo-controlled trial is ongoing for tic reduction from Yi-Gan San, a traditional herbal remedy that has been used to reduce restlessness and agitation in children (NCT03564132). The underlying mechanism for potential tic reduction by these herbal supplements is unknown. 
Acupuncture for TS was the subject of a recent systematic review which found that across 22 RCTs, acupuncture was identified as superior in the overall effectiveness rate, YGTSS score, number of adverse events, and recurrence rates during follow-up [119]. This review had similar conclusions to other systematic reviews on the topic $[120,121]$. According to a recent meta-analysis, NDG (formulated by Zhao) and 5-LGr were found to be probably more likely than

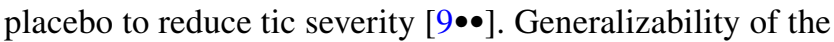
findings of these studies in other tic populations still needs to be established.

Other forms of supplementation also show promise. Taurine, a GABA-receptor agonist, when added to tiapride significantly improved tics compared to placebo, without significantly more adverse events [122]. Whether vitamin D levels correlate with tic severity is unclear [123, 124], but at least one study has demonstrated that vitamin D supplementation led to significant improvement in tic symptoms [125]. Further investigation is needed to confirm benefit and determine if deficiency is needed in order to have potential benefit. In addition to supplementation, a small open-label study described an oral splint (typically used to treat temporomandibular joint disorders) as being helpful for tics. The authors hypothesized that proprioceptive input to the insular cortex might have a modulating effect on tics but acknowledged that a placebo effect may be contributory [126].

Ongoing Clinical Trials.

There are several active or recent studies regarding novel compounds or innovative treatments for TS. There is an ongoing trial investigating atomoxetine, a noradrenaline reuptake inhibitor, which is hypothesized to improve response inhibition in individuals with TS (NCT04354103). AZD5213 is an H3-receptor antagonist that has been assessed for safety and tolerability in the TS population (NCT01904773) but unfortunately has not shown any significant difference compared to placebo. Pimavanserin is a serotonin receptor inverse agonist currently being investigated in an open-label phase 1 pilot study (NCT04794413). Since serotonin is low in co-occurring conditions such as depression, anxiety, and OCD, this medication may be an appropriate treatment choice for patients with TS.

There have also been studies investigating the gut-brain axis. Lactobacillus plantarum PS128 is a probiotic that can modulate neurotransmitter levels in the brain [127]. At least one study has demonstrated improvement in oppositional defiant behaviors in individuals with autism [127], and a trial is currently underway to investigate whether PS128 can reduce tic severity in patients with TS (NCT04805385). Similarly, a case report and an open-label study found that $4 / 5$ patients had significant reduction in YGTSS scores following fecal microbiota transplantation [128, 129].

Studies have also evaluated whether medication can augment behavioral therapies. D-cycloserine is an antibiotic which has been shown to enhance learning. A recent study demonstrated significant tic reduction with D-cycloserine + HRT compared to placebo + HRT [130]. A follow-up study is underway to determine if there are long-lasting effects when D-cycloserine is provided prior to the start of each HRT session (NCT04357951).

There is a great deal of potential to continue improving the pharmacologic treatments available for TS. Although results for VMAT2 inhibitor studies have been disappointing, studies of ecopipam, cannabinoids, intravenous valproic acid, adjunctive taurine, vitamin $\mathrm{D}$, and $\mathrm{D}$-cycloserine have all demonstrated potential therapeutic benefit [131]. Larger, placebo-controlled studies are needed to confirm these findings.

\section{Non-invasive Brain Stimulation (NIBS)}

Though not yet having a role in routine clinical care of TS, the following NIBS have been studied: transcranial magnetic stimulation, transcranial direct current stimulation, and peripheral nerve stimulation.

\section{Transcranial Magnetic Stimulation (TMS)}

Repetitive transcranial magnetic simulation (rTMS) at frequencies of $5 \mathrm{~Hz}$ and higher leads to excitatory modulation, whereas rTMS at low frequencies of $1 \mathrm{~Hz}$ leads to inhibitory modulation. Many case reports and open-label studies using inhibitory stimulation targeted at the supplementary motor area (SMA) demonstrate very promising results [132-138], while other studies have shown no significant differences following rTMS [139, 140], and RCTs have shown trends toward improvement in tics without significant differences between active and sham stimulation (Table 2) [135, 141]. A more recent randomized rTMS study which targeted the bilateral parietal cortex showed significant improvements in tic scores compared to sham stimulation [142]. One meta-analysis concluded that rTMS appears to be an appropriate option for treatment-resistant tic [143]. rTMS may also be a tool to address comorbid symptoms, including OCD [144-146]. Other innovative approaches include combining rTMS with CBIT, of which three trials are actively recruiting (NCT04578912, NCT04795908, NCT03844919). rTMS appears to be safe in adult and pediatric populations [133, 134, 136, 141]. However, heterogeneity between stimulation targets, number of pulses, and sample size may account for variability in outcomes, and further work is needed to determine optimal stimulation parameters. 


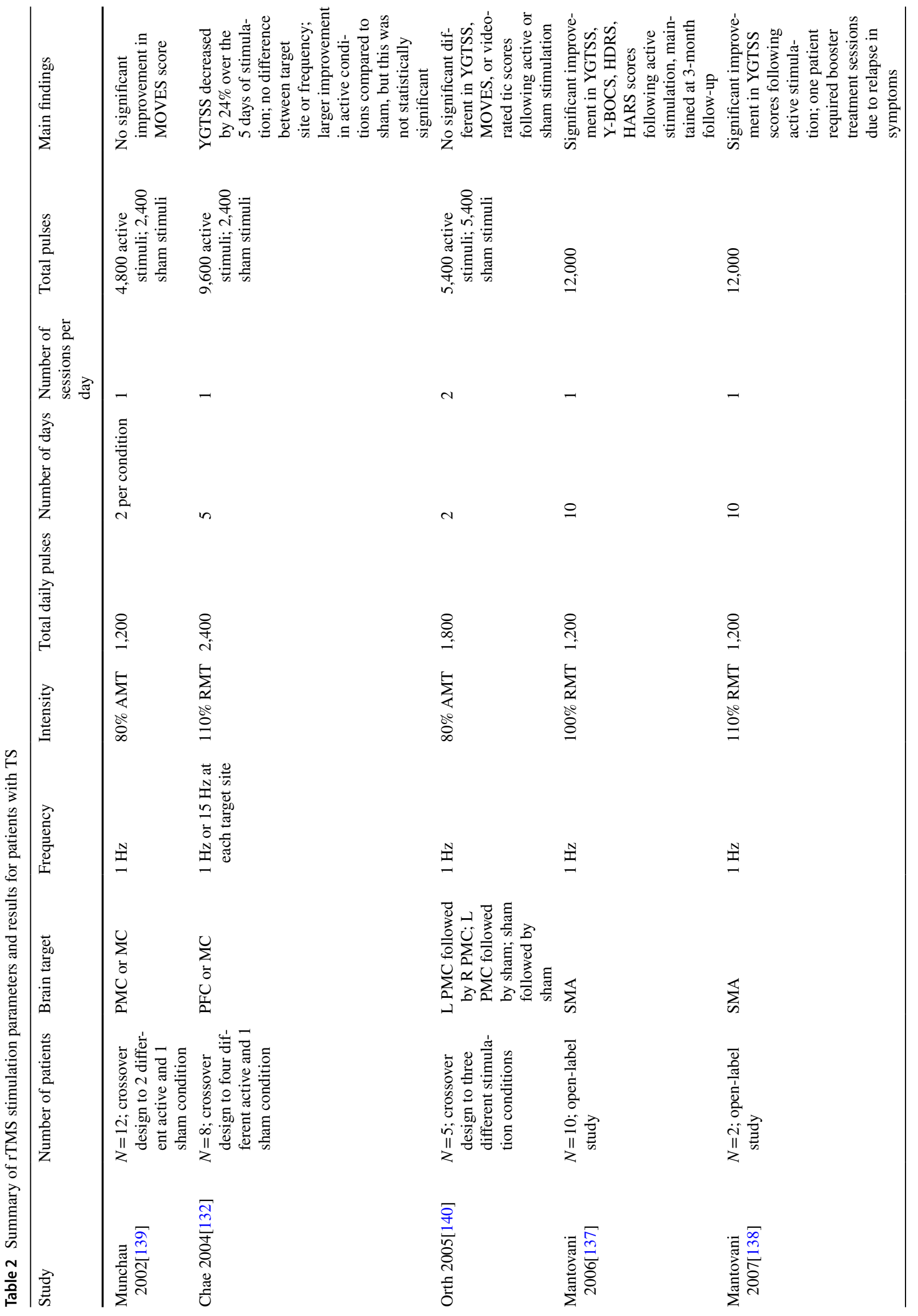




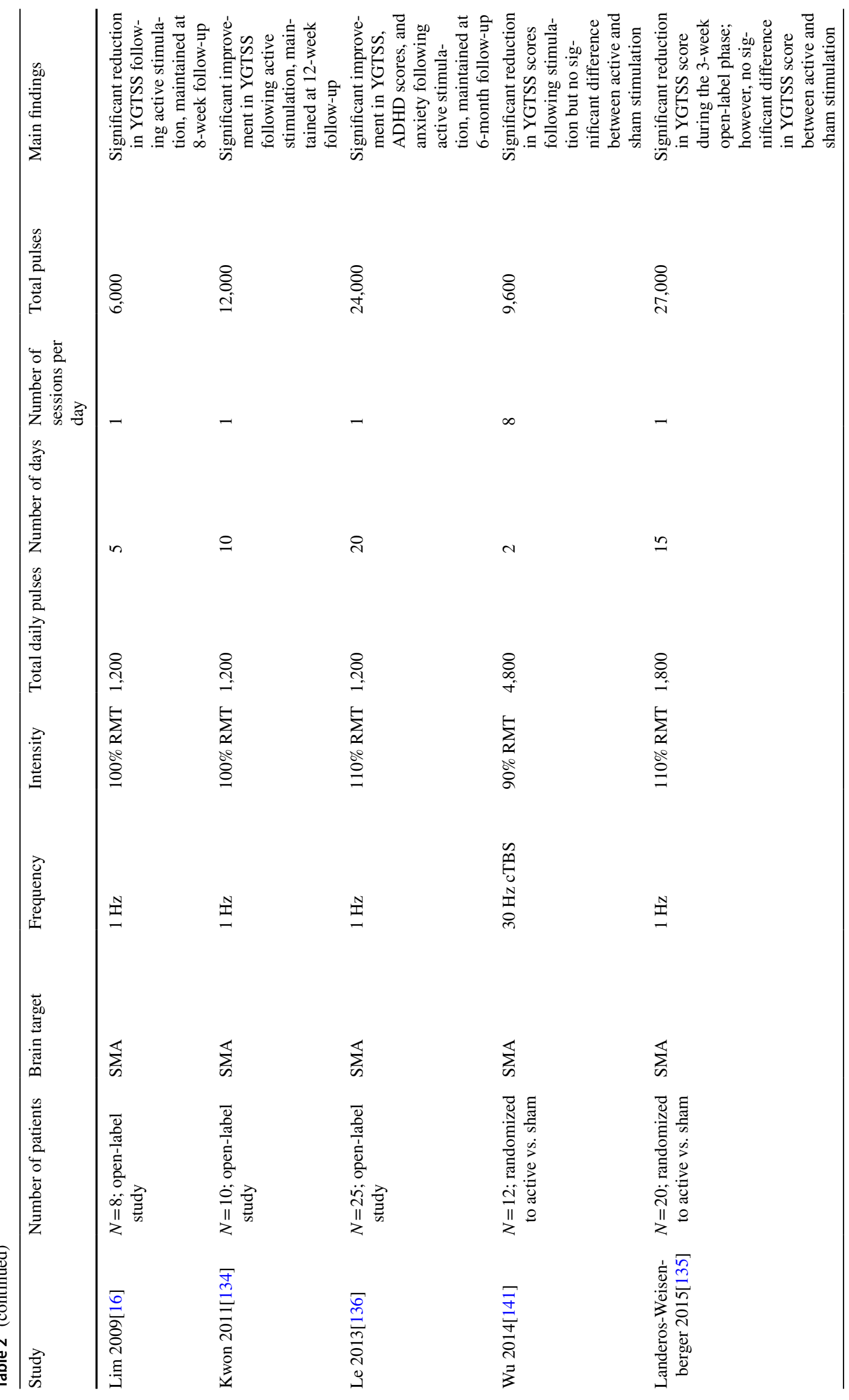




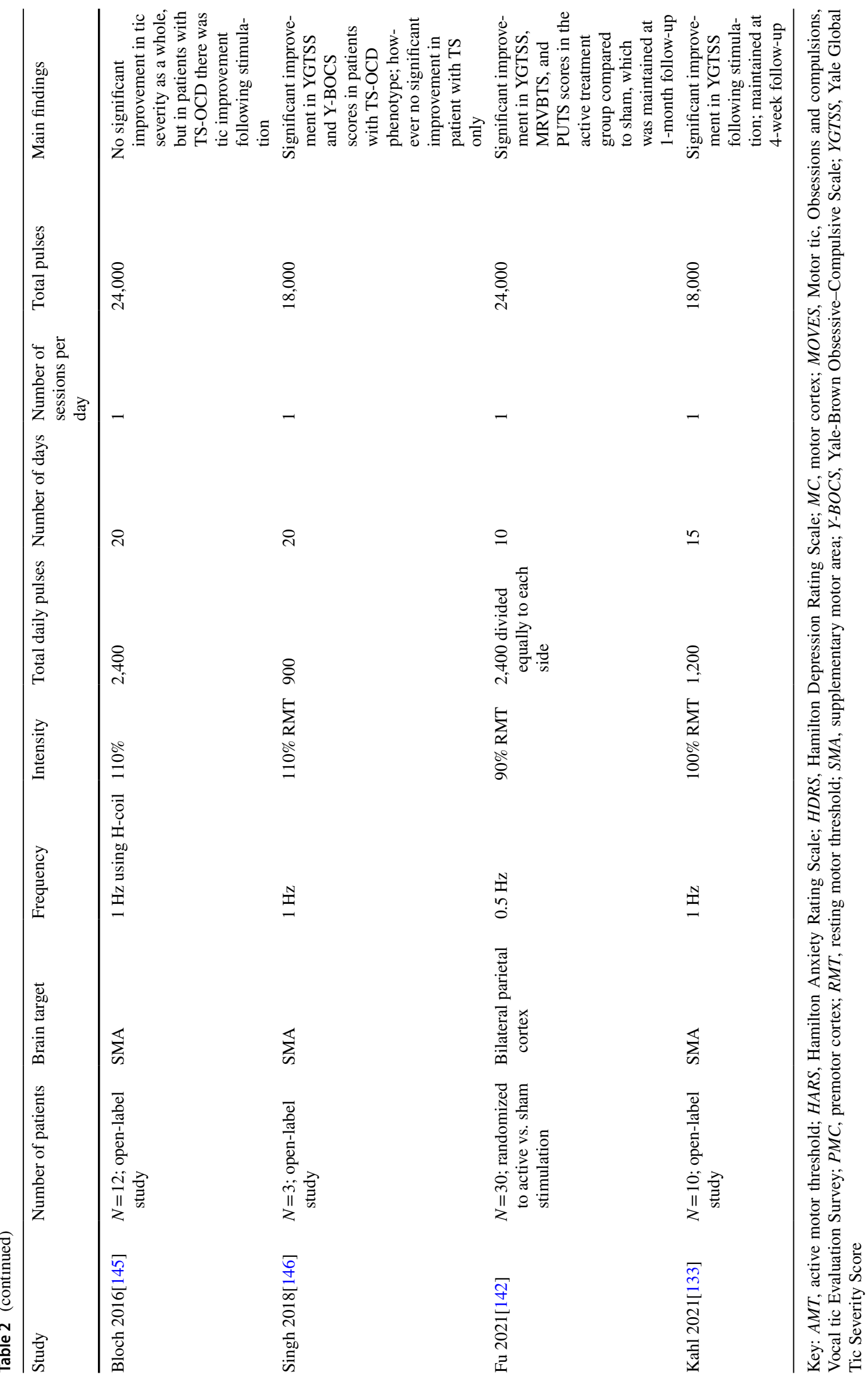




\section{Transcranial Direct Current Stimulation (tDCS)}

Transcranial direct current stimulation (tDCS) uses constant, low current delivered via electrodes attached directly to the scalp. Anodal stimulation increases cortical excitability, whereas cathodal stimulation decreases cortical excitability [147]. As opposed to rTMS, which is expensive, requires specialized training to administer, and travels to a center which has a TMS machine, tDCS is cheap, portable, and easy to administer [147]. Thus far, results have been heterogenous, with many studies demonstrating significant improvement in tic severity following active stimulation [147-152], but only a few demonstrate a significant difference between active and sham stimulation (Table 3) [148, 149]. In addition, many studies were of open-label study design, so it is unclear how much a placebo response led to the improvement in tic severity [151-153]. Currently, one trial is actively recruiting to assess efficacy of $1 \mathrm{~mA}$ tDCS to the SMA (NCT03401996).

\section{Peripheral Nerve Stimulation}

Case reports of patients who were treated with vagal nerve stimulation (VNS) for unrelated causes found that tics also improved when the VNS was turned on [154, 155]. More recently, a case report used transcutaneous VNS combined with breathing exercises to reduce tics [156]. It is currently unclear how VNS influences tics but may be through reduction of the "signal-to-noise ratio" hypothesized to help decipher appropriate motor signals from background noise [157].

It is also known that certain frequency bands, in particular alpha or $\mathrm{mu}(8-14 \mathrm{~Hz})$ and beta $(15-30 \mathrm{~Hz})$, are associated with suppression of movement, and entraining these cortical oscillations could theoretically lead to the suppression of tics [158]. In a recent study, rhythmic pulses delivered at $12 \mathrm{~Hz}$ to the median nerve led to entrainment of mu-band oscillations in the brain and significant reduction in tic frequency and severity as well as the urge to tic [159]. A follow-up, sham-controlled study is currently recruiting in an attempt to replicate these results (NCT04731714).

\section{Cranial Electrotherapy Stimulation (CES)}

Cranial electrotherapy stimulation is a technique which uses a small handheld device to stimulate the brain with a small amount of current. At least one study has combined CES with functional MRI to demonstrate stronger functional connectivity in the anterior cingulate cortex and weaker activity in the SMA, suggesting that CES may suppress disinhibited brain activity associated with TS [160]. A randomized, double-blind, sham-controlled trial known as the Study of CES as an Add-on Treatment for Tic Disorders (SCATT study) is currently underway to determine if CES is a therapeutically meaningful tool to reduce tic severity (NCT03705988).

\section{Deep Brain Stimulation (DBS)}

Approximately 5\% of patients with TS are refractory to more conservative therapies, and DBS may therefore be a valuable treatment option [161]. However, it is important to be aware of patient selection, target selection, and surgical complications before proceeding with surgical intervention for TS.

\section{Candidate Selection}

Guidelines for DBS candidate selection for TS were published in 2015 and include 5 main components: (1) a diagnosis of TS which fulfills DSM V criteria made by a clinician with expertise in tic disorders; (2) tics cause significant disability in daily life; (3) YGTSS severity is $\geq 35$ for at least 1 year; (4) patients have tried and failed conservative treatment in at least three different medication classes and behavioral therapy; and (5) comorbid symptoms such as ADHD and OCD are stable for at least 6 months [162].

These recommendations were refined further recently. First, the presence of malignant tics may not be captured by a YGTSS score, and therefore, tics leading to $\geq 2$ emergency department visits or 1 hospitalization may also fulfill the tic severity requirement $[163 \bullet \bullet$. Second, using quality of life scales to determine if the tics or comorbid symptoms are the

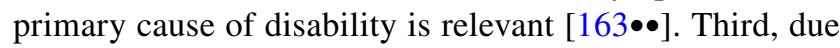
to known fluctuations of tics, duration of treatment attempt should be at least 4-12 weeks [163••].

Although the natural history of TS suggests tics may improve with age and without surgical intervention, there is growing evidence that DBS is safe and efficacious in the pediatric TS population [164, 165, 166•]. DBS has been used to successfully treat patients as young as 12 years of age [165]. Early intervention with DBS may reduce the risk of tic-induced social isolation, minimize harm from malignant tics, and minimize the impact of tics in the academic and professional setting during crucial developmental years [164]. Although there are no strict age cutoffs for DBS in the TS population, the decision to surgically intervene in the pediatric population remains a topic of controversy, and it is recommended that a local ethics committee review cases for patients 18 years old or younger $[162,166 \bullet, 167]$.

\section{International TS DBS Registry}

In collaboration with the Tourette Association of America (TAA), several centers joined together in 2012 to create the International TS DBS Registry [168]. There are currently 


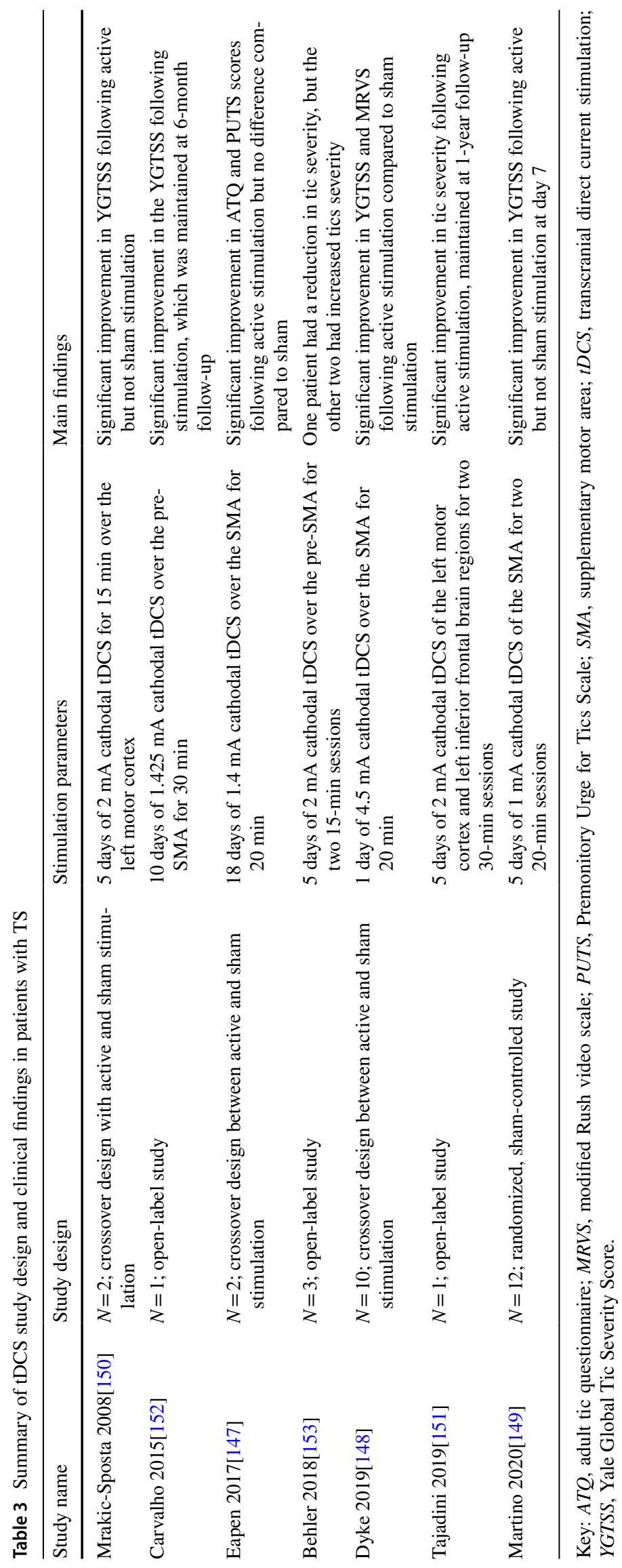


34 different centers contributing data, with 340 registered patients representing 700 DBS leads. The majority of patients have been implanted with bilateral leads, and collectively, a 44\% decrease in total YGTSS score across all targets 1 year following DBS surgery compared to baseline has been recorded (https://tourettedeepbrainstimulationre gistry.ese.ufhealth.org/, accessed 11/4/2021). Both motor and vocal tics demonstrate improvement. The strengths of the TS registry are that it pools cases from across the globe to generate meaningful comparisons between patients, with the goal of providing recommendations for optimal patient and target selection, sharing effective stimulation paradigms, and facilitating regulatory approval [168].

\section{Target Selection}

At least 9 different target sites have been reported in the literature, with the thalamus, anterior globus pallidus internus (aGPi), and nucleus accumbens and anterior internal capsule (ALIC-NAc) as some of the most common targets [167]. Given the complexity and heterogeneity amongst patients with TS, identifying one specific target site for all patients with TS may not be feasible or productive. In fact, understanding individual differences in patients with TS may lead to individualizing the DBS target locations for each patient. For example, tic-predominant TS may be more effectively modulated by thalamic targets, whereas TS with predominant comorbid symptoms may be more effectively modulated by pallidal or ALIC-NAc targets, although further studies are needed to support these observations [167, 169-171].

\section{DBS Outcomes}

Overall, there is a $30-50 \%$ improvement in tics following DBS, regardless of target $[161,172]$. There have been a number of small studies targeting the thalamus [173-178] and GPi $[176,179,180]$ that have demonstrated significant improvement in tic severity. A recent study comparing active and sham stimulation in 8 adult TS patients demonstrated significantly more tic reduction in the active stimulation phase compared to the sham stimulation phase [181]. Combining thalamic and pallidal stimulation did not significantly reduce tics more compared to either type of stimulation alone [182]. In addition, younger age, lower baseline YGTSS, and more severe baseline impairment scores have been shown to predict better DBS outcomes [166•, 169, 181]. Complications from DBS in the TS population occur at similar rates to DBS for other indications [167].

\section{Adaptive Stimulation}

Local field potentials (LFPs) have specific characteristics that correlate with tics and can theoretically be analyzed by the DBS system in a "closed-loop" paradigm to adjust stimulation parameters independently [183]. Bursts of oscillations in the theta range have been associated with worse motor tic severity [184]. Adaptive stimulation minimizes the amount of unwanted stimulation when patients are in a tic-free state and also reduces the power requirements of the IPG [170]. At least one case report demonstrated significant tic reduction with adaptive neurostimulation in response to a $5-15 \mathrm{~Hz}$ oscillatory band, which was comparable to the tic reduction seen with scheduled stimulation, as well as a $63 \%$ improvement in the estimated battery life [185].

\section{Conclusions}

Treatment options have greatly evolved over the past several decades, enabling more opportunities to improve the quality of life for patients with TS. Modifications to existing therapies have enabled behavioral interventions to be more accessible through virtual CBIT platforms, condensing the number of CBIT sessions to occur over a shorter timeframe and providing behavioral therapy in a group setting. These modifications are especially relevant during the COVID-19 pandemic, in which resource allocation and adaptation to telemedicine are paramount. There are several potentially promising pharmacologic options on the horizon which may expand the ability to reduce tics, hopefully with less adverse effects. In addition, there are many CAM options via TCM or vitamin supplementation that are low-risk and may expand the options for primary or adjuvant therapy. Finally, the future of the neuromodulation realm carries many exciting developments, including the use of NIBS to ameliorate tics as well as closed-loop DBS which can tailor stimulation to a patient's unique physiology. While the most effective treatment for TS still depends on the individual symptoms and needs of the patient, these behavioral, pharmacologic, and neuromodulatory developments will continue to pave the way for the future treatment of TS.

Key: $A D H D$, attention deficit hyperactivity disorder; $C B I T$, Comprehensive Behavioral Intervention for Tics; COSA, Child Occupational Self-Assessment; CTD, chronic tic disorder; $E R P$, exposure response prevention; $H R T$, habit reversal training; $P S T$, psychoeducation and supportive therapy; TS, Tourette syndrome; YGTSS, Yale Global Tic Severity Scale.

\section{Compliance with Ethical Standards}

Conflict of Interest The authors have no disclosures to report relevant to the content of this paper. 
Human and Animal Rights and Informed Consent This article does not contain any studies with human or animal subjects performed by any of the authors.

\section{References}

Papers of particular interest, published recently, have been highlighted as:

- Of importance

$\bullet$ Of major importance

1. Yadegar M, Guo S, Ricketts EJ, Zinner SH. Assessment and management of tic disorders in pediatric primary care settings. Curr Dev Disord Rep. 2019;6(3):159-72. https://doi.org/10. 1007/s40474-019-00168-8.

2. Nussey C, Pistrang N, Murphy T. How does psychoeducation help? A review of the effects of providing information about Tourette syndrome and attention-deficit/hyperactivity disorder. Child Care Health Dev. 2013;39(5):617-27. https://doi.org/10. 1111/cch.12039.

3. Chistol A LO. The role of family psychoeducation in the management of tics and tic-related impairment in grade school children. Abstracts of the ENCP Workshop for Junior Scientists. 2018

4. Cen SS, Yu J, Wang Q, Deeb W, Wang KL, Shukla AW, et al. Multidisciplinary telemedicine care for Tourette syndrome: minireview. Front Neurol. 2020;11: 573576. https://doi.org/10. 3389/fneur.2020.573576.

5. Conte G, Valente F, Fioriello F, Cardona F. Rage attacks in Tourette syndrome and chronic tic disorder: a systematic review. Neurosci Biobehav Rev. 2020;119:21-36. https://doi.org/10. 1016/j.neubiorev.2020.09.019.

6. Cauberghe V, Van Wesenbeeck I, De Jans S, Hudders L, Ponnet $\mathrm{K}$. How adolescents use social media to cope with feelings of loneliness and anxiety during COVID-19 lockdown. Cyberpsychol Behav Soc Netw. 2021;24(4):250-7. https://doi.org/10. 1089/cyber.2020.0478.

7. Heyman I, Liang H, Hedderly T. COVID-19 related increase in childhood tics and tic-like attacks. Arch Dis Child. 2021. https:// doi.org/10.1136/archdischild-2021-321748.

8. Perkins V, Coulson NS, Davies EB. Using online support communities for Tourette syndrome and tic disorders: online survey of users' experiences. J Med Internet Res. 2020;22(11):e18099. https://doi.org/10.2196/18099.

9.•• Pringsheim T, Okun MS, Müller-Vahl K, Martino D, Jankovic J, Cavanna AE et al. Practice guideline recommendations summary: treatment of tics in people with Tourette syndrome and chronic tic disorders. Neurology. 2019;92(19):896-906. doi:https://doi.org/10.1212/WNL.0000000000007466. Most recent AAN practice guidelines for the treatment of TS

10.• Andrén P, Jakubovski E, Murphy TL, Woitecki K, Tarnok Z, Zimmerman-Brenner $\mathrm{S}$ et al. European clinical guidelines for Tourette syndrome and other tic disorders-version 2.0. Part II: psychological interventions. Eur Child Adolesc Psychiatry. 2021. https://doi.org/10.1007/s00787-021-01845-z. Most recent European guidelines for the treatment of TS

11. Liu S, Li Y, Cui Y. Review of habit reversal training for tic disorders. Pediatr Investig. 2020;4(2):127-32. https://doi.org/10. 1002/ped4.12190.

12. Wu MS, McGuire JF. Psychoeducation about tic disorders and treatment. The clinician's guide to treatment and management of youth with Tourette syndrome and tic disorder. San Diego, CA, US: Elsevier Academic Press; 2018. p. 21-41.
13.••Pringsheim T, Holler-Managan Y, Okun MS, Jankovic J, Piacentini J, Cavanna AE et al. Comprehensive systematic review summary: treatment of tics in people with Tourette syndrome and chronic tic disorders. Neurology. 2019;92(19):90715. doi:https://doi.org/10.1212/WNL.0000000000007467. Recent systematic review that covers many details about efficacy and safety of treatments for TS

14.• Steeves T, McKinlay BD, Gorman D, Billinghurst L, Day L, Carroll A, et al. Canadian guidelines for the evidence-based treatment of tic disorders: behavioural therapy, deep brain stimulation, and transcranial magnetic stimulation. Can $\mathrm{J}$ Psychiatry. 2012;57(3):144-51. https://doi.org/10.1177/07067 4371205700303. Most recent Canadian guidelines for the treatment of TS

15. Rizzo R, Pellico A, Silvestri PR, Chiarotti F, Cardona F. A randomized controlled trial comparing behavioral, educational, and pharmacological treatments in youths with chronic tic disorder or Tourette syndrome. Front Psychiatry. 2018;9:100. https://doi.org/10.3389/fpsyt.2018.00100.

16. Kim KM, Bae E, Lee J, Park TW, Lim MH. A review of cognitive and behavioral interventions for tic disorder. Soa Chongsonyon Chongsin Uihak. 2021;32(2):51-62. https://doi.org/10. 5765/jkacap.200042.

17. Robertson MM. Gilles de la Tourette syndrome: the complexities of phenotype and treatment. Br J Hosp Med (Lond). 2011;72(2):100-7. https://doi.org/10.12968/hmed.2011.72.2. 100.

18. Verdellen CW, Keijsers GP, Cath DC, Hoogduin CA. Exposure with response prevention versus habit reversal in Tourette's syndrome: a controlled study. Behav Res Ther. 2004;42(5):501-11. https://doi.org/10.1016/S0005-7967(03) 00154-2.

19. Deckersbach T, Rauch S, Buhlmann U, Wilhelm S. Habit reversal versus supportive psychotherapy in Tourette's disorder: a randomized controlled trial and predictors of treatment response. Behav Res Ther. 2006;44(8):1079-90. https://doi.org/10.1016/j. brat.2005.08.007.

20. Wilhelm S, Deckersbach T, Coffey BJ, Bohne A, Peterson AL, Baer L. Habit reversal versus supportive psychotherapy for Tourette's disorder: a randomized controlled trial. Am J Psychiatry. 2003;160(6):1175-7. https://doi.org/10.1176/appi.ajp.160.6. 1175 .

21. O'Connor KP, Brault M, Robillard S, Loiselle J, Borgeat F, Stip E. Evaluation of a cognitive-behavioural program for the management of chronic tic and habit disorders. Behav Res Ther. 2001;39(6):667-81. https://doi.org/10.1016/s0005-7967(00) 00048-6.

22. Seragni G, Chiappedi M, Bettinardi B, Zibordi F, Colombo T, Reina C, et al. Habit reversal training in children and adolescents with chronic tic disorders: an Italian randomized, single-blind pilot study. Minerva Pediatr. 2018;70(1):5-11. https://doi.org/ 10.23736/S0026-4946.16.04344-9.

23. Viefhaus P, Feldhausen M, Görtz-Dorten A, Volk H, Döpfner M, Woitecki K. Efficacy of habit reversal training in children with chronic tic disorders: a within-subject analysis. Behav Modif. 2020;44(1):114-36. https://doi.org/10.1177/0145445518796203.

24. McGuire JF, Piacentini J, Scahill L, Woods DW, Villarreal R, Wilhelm S, et al. Bothersome tics in patients with chronic tic disorders: characteristics and individualized treatment response to behavior therapy. Behav Res Ther. 2015;70:56-63. https://doi. org/10.1016/j.brat.2015.05.006.

25. McGinty HLDNA, Park JM, Storch EA. Living with tics: a cognitive-behavioral approach to improving coping and reducing tic severity in a young adult with Tourette disorder. Clin Case Stud. 2012;11(3):218-33. 
26. Scahill L, Woods DW, Himle MB, Peterson AL, Wilhelm S, Piacentini JC, et al. Current controversies on the role of behavior therapy in Tourette syndrome. Mov Disord. 2013;28(9):117983. https://doi.org/10.1002/mds.25488.

27. Petruo V, Bodmer B, Bluschke A, Münchau A, Roessner V, Beste C. Comprehensive behavioral intervention for tics reduces perception-action binding during inhibitory control in Gilles de la Tourette syndrome. Sci Rep. 2020;10(1):1174. https://doi.org/ 10.1038/s41598-020-58269-z.

28. Woods DW, Piacentini JC, Scahill L, Peterson AL, Wilhelm S, Chang S, et al. Behavior therapy for tics in children: acute and long-term effects on psychiatric and psychosocial functioning. J Child Neurol. 2011;26(7):858-65. https://doi.org/10.1177/08830 73810397046.

29. Wilhelm S, Peterson AL, Piacentini J, Woods DW, Deckersbach T, Sukhodolsky DG, et al. Randomized trial of behavior therapy for adults with Tourette syndrome. Arch Gen Psychiatry. 2012;69(8):795-803. https://doi.org/10.1001/archgenpsychiatry. 2011.1528.

30. Piacentini J, Woods DW, Scahill L, Wilhelm S, Peterson AL, Chang S, et al. Behavior therapy for children with Tourette disorder: a randomized controlled trial. JAMA. 2010;303(19):192937. https://doi.org/10.1001/jama.2010.607.

31. Espil F. A long term follow up to a randomized controlled trial of comprehensive behavioral intervention for tics: University of Wisconsin-Milwaukee; 2015.

32. McGuire JF, Ricketts EJ, Scahill L, Wilhelm S, Woods DW, Piacentini J, et al. Effect of behavior therapy for Tourette's disorder on psychiatric symptoms and functioning in adults. Psychol Med. 2020;50(12):2046-56. https://doi.org/10.1017/S0033 291719002150.

33. Bennett SM, Capriotti M, Bauer C, Chang S, Keller AE, Walkup $\mathrm{J}$, et al. Development and open trial of a psychosocial intervention for young children with chronic tics: the CBIT-JR Study. Behav Ther. 2020;51(4):659-69. https://doi.org/10.1016/j.beth. 2019.10.004.

34. Singer HS, McDermott S, Ferenc L, Specht M, Mahone EM. Efficacy of parent-delivered, home-based therapy for tics. Pediatr Neurol. 2020;106:17-23. https://doi.org/10.1016/j.pediatrneurol. 2019.12.015.

35. Yates R, Edwards K, King J, Luzon O, Evangeli M, Stark D, et al. Habit reversal training and educational group treatments for children with Tourette syndrome: a preliminary randomised controlled trial. Behav Res Ther. 2016;80:43-50. https://doi.org/ 10.1016/j.brat.2016.03.003.

36. Dabrowski J, King J, Edwards K, Yates R, Heyman I, Zimmerman-Brenner S, et al. The long-term effects of group-based psychological interventions for children with Tourette syndrome: a randomized controlled trial. Behav Ther. 2018;49(3):331-43. https://doi.org/10.1016/j.beth.2017.10.005.

37. Nissen JB, Kaergaard M, Laursen L, Parner E, Thomsen PH. Combined habit reversal training and exposure response prevention in a group setting compared to individual training: a randomized controlled clinical trial. Eur Child Adolesc Psychiatry. 2019;28(1):57-68. https://doi.org/10.1007/s00787-018-1187-z.

38. Heijerman-Holtgrefe AP, Verdellen CWJ, van de Griendt JMTM, Beljaars LPL, Kan KJ, Cath D, et al. Tackle your tics: pilot findings of a brief, intensive group-based exposure therapy program for children with tic disorders. Eur Child Adolesc Psychiatry. 2021;30(3):461-73. https://doi.org/10.1007/ s00787-020-01532-5.

39. Leclerc JB, O'Connor KP, J-Nolin G, Valois P, Lavoie ME. The effect of a new therapy for children with tics targeting underlying cognitive, behavioral, and physiological processes. Front Psychiatry. 2016;7:135. doi:https://doi.org/10.3389/fpsyt.2016. 00135.
40. O'Connor K, Lavoie M, Blanchet P, St-Pierre-Delorme M. Evaluation of a cognitive psychophysiological model for management of tic disorders: an open trial. Br J Psychiatry. 2016;209(1):76-83. https://doi.org/10.1192/bjp.bp.114.154518.

41. Chen CW, Wang HS, Chang HJ, Hsueh CW. Effectiveness of a modified comprehensive behavioral intervention for tics for children and adolescents with Tourette's syndrome: a randomized controlled trial. J Adv Nurs. 2020;76(3):903-15. https://doi.org/ 10.1111/jan.14279.

42. Blount THRJ, Peterson AL. Intensive outpatient comprehensive behavioral intervention for tics: a clinical replication series. Cogn Behav Pract. 2017;25(1):156-67.

43. Blount TH, Lockhart AL, Garcia RV, Raj JJ, Peterson AL. Intensive outpatient comprehensive behavioral intervention for tics: a case series. World J Clin Cases. 2014;2(10):569-77. https://doi. org/10.12998/wjcc.v2.i10.569.

44. Himle MB, Freitag M, Walther M, Franklin SA, Ely L, Woods DW. A randomized pilot trial comparing videoconference versus face-to-face delivery of behavior therapy for childhood tic disorders. Behav Res Ther. 2012;50(9):565-70. https://doi.org/ 10.1016/j.brat.2012.05.009.

45. Ricketts EJ, Goetz AR, Capriotti MR, Bauer CC, Brei NG, Himle $\mathrm{MB}$, et al. A randomized waitlist-controlled pilot trial of voice over Internet protocol-delivered behavior therapy for youth with chronic tic disorders. J Telemed Telecare. 2016;22(3):153-62. https://doi.org/10.1177/1357633X15593192.

46. Andrén P, Aspvall K, Fernández de la Cruz L, Wiktor P, Romano $\mathrm{S}$, Andersson $\mathrm{E}$ et al. Therapist-guided and parent-guided internet-delivered behaviour therapy for paediatric Tourette's disorder: a pilot randomised controlled trial with long-term followup. BMJ Open. 2019;9(2):e024685. doi:https://doi.org/10.1136/ bmjopen-2018-024685.

47. Conelea CA, Wellen BCM. Tic treatment goes tech: a review of TicHelper.com. Cogn Behav Pract. 2017;24(3):374-81. doi:https://doi.org/10.1016/j.cbpra.2017.01.003.

48. Black JK, Koller JM, Black KJ. TicTimer software for measuring tic suppression. F1000Res. 2017;6:1560. doi:https://doi.org/10. 12688/f1000research.12327.2.

49. Hall CL, Davies EB, Andrén P, Murphy T, Bennett S, Brown $\mathrm{BJ}$, et al. Investigating a therapist-guided, parent-assisted remote digital behavioural intervention for tics in children and adolescents-'Online Remote Behavioural Intervention for Tics' (ORBIT) trial: protocol of an internal pilot study and singleblind randomised controlled trial. BMJ Open. 2019;9(1): e027583. https://doi.org/10.1136/bmjopen-2018-027583.

50. Jakubovski E, Reichert C, Karch A, Buddensiek N, Breuer D, Müller-Vahl K. The ONLINE-TICS study protocol: a randomized observer-blind clinical trial to demonstrate the efficacy and safety of Internet-delivered behavioral treatment for adults with chronic tic disorders. Front Psychiatry. 2016;7:119. https:// doi.org/10.3389/fpsyt.2016.00119.

51. Hawksley J, Cavanna AE, Nagai Y. The role of the autonomic nervous system in Tourette syndrome. Front Neurosci. 2015;9:117. https://doi.org/10.3389/fnins.2015.00117.

52. Nagai Y, Cavanna AE, Critchley HD, Stern JJ, Robertson MM, Joyce EM. Biofeedback treatment for Tourette syndrome: a preliminary randomized controlled trial. Cogn Behav Neurol. 2014;27(1):17-24. https://doi.org/10.1097/WNN.0000000000 000019.

53. Nagai Y, Cavanna A, Critchley HD. Influence of sympathetic autonomic arousal on tics: implications for a therapeutic behavioral intervention for Tourette syndrome. J Psychosom Res. 2009;67(6):599-605. https://doi.org/10.1016/j.jpsychores.2009. 06.004 .

54. Sukhodolsky DG, Walsh C, Koller WN, Eilbott J, Rance M, Fulbright RK, et al. Randomized, sham-controlled trial of 
real-time functional magnetic resonance imaging neurofeedback for tics in adolescents with Tourette syndrome. Biol Psychiatry. 2020;87(12):1063-70. https://doi.org/10.1016/j.biopsych.2019. 07.035 .

55. Seideman MF, Seideman TA. A review of the current treatment of Tourette syndrome.J Pediatr Pharmacol Ther. 2020;25(5):40112. doi:https://doi.org/10.5863/1551-6776-25.5.401.

56. Ueda K, Black KJ. A comprehensive review of tic disorders in children. J Clin Med. 2021;10(11). https://doi.org/10.3390/ $\mathrm{jcm} 10112479$. This paper gives a good overview of various different treatments for tic disorders in general

57. Essoe JK, Grados MA, Singer HS, Myers NS, McGuire JF. Evidence-based treatment of Tourette's disorder and chronic tic disorders. Expert Rev Neurother. 2019;19(11):1103-15. https:// doi.org/10.1080/14737175.2019.1643236. Similarly, this paper discusses multiple aspects of treatments for tic disorders

58. Goetz CG, Tanner CM, Wilson RS, Carroll VS, Como PG, Shannon KM. Clonidine and Gilles de la Tourette's syndrome: double-blind study using objective rating methods. Ann Neurol. 1987;21(3):307-10. https://doi.org/10.1002/ana.410210313.

59. Leckman JF, Hardin MT, Riddle MA, Stevenson J, Ort SI, Cohen DJ. Clonidine treatment of Gilles de la Tourette's syndrome. Arch Gen Psychiatry. 1991;48(4):324-8. https://doi.org/10.1001/ archpsyc.1991.01810280040006.

60. Group TsSS. Treatment of ADHD in children with tics: a randomized controlled trial. Neurology. 2002;58(4):527-36. https:// doi.org/10.1212/wnl.58.4.527.

61. Du YS, Li HF, Vance A, Zhong YQ, Jiao FY, Wang HM, et al. Randomized double-blind multicentre placebo-controlled clinical trial of the clonidine adhesive patch for the treatment of tic disorders. Aust N Z J Psychiatry. 2008;42(9):807-13. https://doi. org/10.1080/00048670802277222.

62. Song PP, Jiang L, Li XJ, Hong SQ, Li SZ, Hu Y. The efficacy and tolerability of the clonidine transdermal patch in the treatment for children with tic disorders: a prospective, open, single-group, self-controlled study. Front Neurol. 2017;8:32. https://doi.org/ 10.3389/fneur.2017.00032.

63. Yang C, Kang B, Yu D, Zhao L, Zhang L. Effectiveness and safety of a clonidine adhesive patch for children with tic disorders: study in a real-world practice. Front Neurol. 2020;11:361. https://doi.org/10.3389/fneur.2020.00361.

64. Kang H, Zhang YF, Jiao FY, Guo XY, Gao XM. Efficacy of clonidine transdermal patch for treatment of Tourette's syndrome in children. Zhongguo Dang Dai Er Ke Za Zhi. 2009;11(7):537-9.

65. Jiao F, Zhang X, Wang J. Clinical observation on treatment of Tourette syndrome in Chinese children by clonidine adhesive patch. Eur J Paediatr Neurol. 2016;20(1):80-4. https://doi.org/ 10.1016/j.ejpn.2015.10.002

66. Guo JM, Shi XX, Yang SW, Qian QF, Huang Y, Xie YQ, et al. Efficacy of clonidine transdermal patch in treatment of moderate to severe tic disorders in children. Zhongguo Dang Dai Er Ke Za Zhi. 2017;19(7):786-9.

67. Boon-yasidhi V, Kim YS, Scahill L. An open-label, prospective study of guanfacine in children with ADHD and tic disorders. J Med Assoc Thai. 2005;88(Suppl 8):S156-62.

68. Scahill L, Chappell PB, Kim YS, Schultz RT, Katsovich L, Shepherd E, et al. A placebo-controlled study of guanfacine in the treatment of children with tic disorders and attention deficit hyperactivity disorder. Am J Psychiatry. 2001;158(7):1067-74. https://doi.org/10.1176/appi.ajp.158.7.1067.

69. Cummings DD, Singer HS, Krieger M, Miller TL, Mahone EM. Neuropsychiatric effects of guanfacine in children with mild Tourette syndrome: a pilot study. Clin Neuropharmacol. 2002;25(6):325-32. https://doi.org/10.1097/00002826-20021 $1000-00009$
70. Murphy TK, Fernandez TV, Coffey BJ, Rahman O, Gavaletz A, Hanks CE, et al. Extended-release guanfacine does not show a large effect on tic severity in children with chronic tic disorders. J Child Adolesc Psychopharmacol. 2017;27(9):762-70. https:// doi.org/10.1089/cap.2017.0024.

71. Martínez-Granero MA, García-Pérez A, Montañes F. Levetiracetam as an alternative therapy for Tourette syndrome. Neuropsychiatr Dis Treat. 2010;6:309-16. https://doi.org/10.2147/ ndt.s6371.

72. Jankovic J, Jimenez-Shahed J, Brown LW. A randomised, double-blind, placebo-controlled study of topiramate in the treatment of Tourette syndrome. J Neurol Neurosurg Psychiatry. 2010;81(1):70-3. https://doi.org/10.1136/jnnp.2009.185348.

73. Kuo SH, Jimenez-Shahed J. Topiramate in treatment of Tourette syndrome. Clin Neuropharmacol. 2010;33(1):32-4. https://doi. org/10.1097/WNF.0b013e3181c295c1.

74. Awaad YMA, Minarik S. Long-term use of levetiracetam to treat tics in children and adolescents with Tourette syndrome. J Ped Neurol. 2007;5(3):209-14.

75. Smith-Hicks CL, Bridges DD, Paynter NP, Singer HS. A double blind randomized placebo control trial of levetiracetam in Tourette syndrome. Mov Disord. 2007;22(12):1764-70. https://doi. org/10.1002/mds.21615.

76. Hedderick EF, Morris CM, Singer HS. Double-blind, crossover study of clonidine and levetiracetam in Tourette syndrome. Pediatr Neurol. 2009;40(6):420-5. doi:https://doi.org/10.1016/j.pedia trneurol.2008.12.014.

77. Quezada J, Coffman KA. Current approaches and new developments in the pharmacological management of Tourette syndrome. CNS Drugs. 2018;32(1):33-45. https://doi.org/10.1007/ s40263-017-0486-0. A comprehensive overview of the pharmacotherapies used to treat TS

78. Singer HS, Wendlandt J, Krieger M, Giuliano J. Baclofen treatment in Tourette syndrome: a double-blind, placebo-controlled, crossover trial. Neurology. 2001;56(5):599-604. https://doi.org/ 10.1212/wnl.56.5.599.

79. Deeb W, Malaty IA, Mathews CA. Tourette disorder and other tic disorders. Handb Clin Neurol. 2019;165:123-53. https://doi. org/10.1016/B978-0-444-64012-3.00008-3.

80. Gulisano M, Calì PV, Cavanna AE, Eddy C, Rickards H, Rizzo R. Cardiovascular safety of aripiprazole and pimozide in young patients with Tourette syndrome. Neurol Sci. 2011;32(6):12137. https://doi.org/10.1007/s10072-011-0678-1.

81. Yang C, Yi Q, Zhang L, Cui H, Mao J. Safety of aripiprazole for tics in children and adolescents: a systematic review and metaanalysis. Medicine (Baltimore). 2019;98(22): e15816. https:// doi.org/10.1097/MD.0000000000015816.

82. Yang CS, Huang H, Zhang LL, Zhu CR, Guo Q. Aripiprazole for the treatment of tic disorders in children: a systematic review and meta-analysis. BMC Psychiatry. 2015;15:179. https://doi.org/10. 1186/s12888-015-0504-z.

83. Tao D, Zhong T, Ma S, Li J, Li X. Randomized controlled clinical trial comparing the efficacy and tolerability of aripiprazole and sodium valproate in the treatment of Tourette syndrome. Ann Gen Psychiatry. 2019;18:24. https://doi.org/10.1186/ s12991-019-0245-3.

84. Budman CL. The role of atypical antipsychotics for treatment of Tourette's syndrome: an overview. Drugs. 2014;74(11):1177-93. https://doi.org/10.1007/s40265-014-0254-0.

85. Gilbert DL, Budman CL, Singer HS, Kurlan R, Chipkin RE. A D1 receptor antagonist, ecopipam, for treatment of tics in Tourette syndrome. Clin Neuropharmacol. 2014;37(1):26-30. https://doi.org/10.1097/WNF.0000000000000017.

86. Gilbert DL, Murphy TK, Jankovic J, Budman CL, Black KJ, Kurlan RM, et al. Ecopipam, a D1 receptor antagonist, for 
treatment of Tourette syndrome in children: a randomized, placebo-controlled crossover study. Mov Disord. 2018;33(8):127280. https://doi.org/10.1002/mds.27457.

87. Jankovic J, Glaze DG, Frost JD. Effect of tetrabenazine on tics and sleep of Gilles de la Tourette's syndrome. Neurology. 1984;34(5):688-92. https://doi.org/10.1212/wnl.34.5.688.

88. Kenney C, Hunter C, Jankovic J. Long-term tolerability of tetrabenazine in the treatment of hyperkinetic movement disorders. Mov Disord. 2007;22(2):193-7. https://doi.org/10.1002/mds. 21222.

89. Jankovic J, Jimenez-Shahed J, Budman C, Coffey B, Murphy $\mathrm{T}$, Shprecher D, et al. Deutetrabenazine in tics associated with Tourette syndrome. Tremor Other Hyperkinet Mov (N Y). 2016;6:422. https://doi.org/10.7916/D8M32W3H.

90. Farber RH, Angelov A, Kim K, Carmack T, Thai-Cuarto D, Roberts E. Clinical development of valbenazine for tics associated with Tourette syndrome. Expert Rev Neurother. 2021;21(4):393404. https://doi.org/10.1080/14737175.2021.1898948.

91. Szejko N, Jakubovski E, Muller-Vahl K. Possible role of the endocannabinoid system in Tourette syndrome. Recent Advances in Cannabinoid Research. IntechOpen; 2018.

92. Müller-Vahl KR, Schneider U, Koblenz A, Jöbges M, Kolbe H, Daldrup T, et al. Treatment of Tourette's syndrome with Delta 9-tetrahydrocannabinol (THC): a randomized crossover trial. Pharmacopsychiatry. 2002;35(2):57-61. https://doi.org/10. 1055/s-2002-25028.

93. Müller-Vahl KR, Schneider U, Prevedel H, Theloe K, Kolbe H, Daldrup T, et al. Delta 9-tetrahydrocannabinol (THC) is effective in the treatment of tics in Tourette syndrome: a 6-week randomized trial. J Clin Psychiatry. 2003;64(4):459-65. https://doi. org/10.4088/jcp.v64n0417.

94. Curtis A, Clarke CE, Rickards HE. Cannabinoids for Tourette's syndrome. Cochrane Database Syst Rev. 2009(4):CD006565. doi:https://doi.org/10.1002/14651858.CD006565.pub2.

95. Artukoglu BB, Bloch MH. The potential of cannabinoid-based treatments in Tourette syndrome. CNS Drugs. 2019;33(5):41730. https://doi.org/10.1007/s40263-019-00627-1.

96. Milosev LM, Psathakis N, Szejko N, Jakubovski E, Müller-Vahl KR. Treatment of Gilles de la Tourette syndrome with cannabisbased medicine: results from a retrospective analysis and online survey. Cannabis Cannabinoid Res. 2019;4(4):265-74. https:// doi.org/10.1089/can.2018.0050.

97. Jakubovski E, Pisarenko A, Fremer C, Haas M, May M, Schumacher $\mathrm{C}$, et al. The CANNA-TICS study protocol: a randomized multi-center double-blind placebo controlled trial to demonstrate the efficacy and safety of nabiximols in the treatment of adults with chronic tic disorders. Front Psychiatry. 2020;11: 575826. https://doi.org/10.3389/fpsyt.2020.575826.

98. Mueller-Vahl K. ABX-1431, a first-in-class endocannabinoid modulator, improves tics in adult patients with Tourette syndrome. Neurology. 2018;90:e2182-3.

99. Müller-Vahl KR, Fremer C, Beals C, Ivkovic J, Loft H, Schindler C. Monoacylglycerol lipase inhibition in Tourette syndrome: a 12-week, randomized, controlled study. Mov Disord. 2021;36(10):2413-8. https://doi.org/10.1002/mds.28681.

100. Bloch MH, Landeros-Weisenberger A, Johnson JA, Leckman JF. A phase-2 pilot study of a therapeutic combination of $\Delta$. J Neuropsychiatry Clin Neurosci. 2021;33(4):328-36. https://doi. org/10.1176/appi.neuropsych.19080178.

101. Aguirregomozcorta M, Pagonabarraga J, Diaz-Manera J, Pascual-Sedano B, Gironell A, Kulisevsky J. Efficacy of botulinum toxin in severe Tourette syndrome with dystonic tics involving the neck. Parkinsonism Relat Disord. 2008;14(5):443-5. https:// doi.org/10.1016/j.parkreldis.2007.10.007.

102. Trimble MR, Whurr R, Brookes G, Robertson MM. Vocal tics in Gilles de la Tourette syndrome treated with botulinum toxin injections. Mov Disord. 1998;13(3):617-9. https://doi.org/10. 1002/mds.870130348.

103. Scott BL, Jankovic J, Donovan DT. Botulinum toxin injection into vocal cord in the treatment of malignant coprolalia associated with Tourette's syndrome. Mov Disord. 1996;11(4):431-3. https://doi.org/10.1002/mds.870110413.

104. Salloway S, Stewart CF, Israeli L, Morales X, Rasmussen S, Blitzer A, et al. Botulinum toxin for refractory vocal tics. Mov Disord. 1996;11(6):746-8. https://doi.org/10.1002/mds.87011 0627.

105. Jankovic J. Botulinum toxin in the treatment of dystonic tics. Mov Disord. 1994;9(3):347-9. https://doi.org/10.1002/mds. 870090315.

106. Kwak CH, Hanna PA, Jankovic J. Botulinum toxin in the treatment of tics. Arch Neurol. 2000;57(8):1190-3. https://doi.org/ 10.1001/archneur.57.8.1190.

107. Porta M, Maggioni G, Ottaviani F, Schindler A. Treatment of phonic tics in patients with Tourette's syndrome using botulinum toxin type A. Neurol Sci. 2004;24(6):420-3. https://doi.org/10. 1007/s10072-003-0201-4.

108. Rath JJ, Tavy DL, Wertenbroek AA, van Woerkom TC, de Bruijn SF. Botulinum toxin type A in simple motor tics: short-term and long-term treatment-effects. Parkinsonism Relat Disord. 2010;16(7):478-81. https://doi.org/10.1016/j.parkreldis.2009. 11.011 .

109. Marras C, Andrews D, Sime E, Lang AE. Botulinum toxin for simple motor tics: a randomized, double-blind, controlled clinical trial. Neurology. 2001;56(5):605-10. https://doi.org/10.1212/ wnl.56.5.605.

110. Pandey S, Srivanitchapoom P, Kirubakaran R, Berman BD. Botulinum toxin for motor and phonic tics in Tourette's syndrome. Cochrane Database Syst Rev. 2018;1:CD012285. doi:https://doi. org/10.1002/14651858.CD012285.pub2.

111. Patel H, Nguyen K, Lehman E, Mainali G, Duda L, Byler D, et al. Use of complementary and alternative medicine in children with Tourette syndrome. J Child Neurol. 2020;35(8):512-6. https://doi.org/10.1177/0883073820913670.

112. Qi H, Liu R, Zheng W, Zhang L, Ungvari GS, Ng CH et al. Efficacy and safety of traditional Chinese medicine for Tourette's syndrome: a meta-analysis of randomized controlled trials. Asian J Psychiatr. 2020;47:101853. https://doi.org/10.1016/j. ajp.2019.101853.

113.• Wang N, Qin DD, Xie YH, Wu XC, Wang DY, Hang-Yang et al. Traditional Chinese medicine strategy for patients with Tourette syndrome based on clinical efficacy and safety: a metaanalysis of 47 randomized controlled trials. Biomed Res Int. 2021;2021:6630598. https://doi.org/10.1155/2021/6630598. Overview of various TCM approaches forthe treatment of TS

114. Lv J, Zhu Q, Hao Y. The treatment of Choudongning capsule in children with Tourette's syndrome: a double blind and double simulation clinical study (in Chinese). Global Tradit Chin Med. 2013;6:85-6.

115. Yang N, Ma R, Hu SY, Liu H, Yan HM, Xiang XX, et al. Efficacy and safety of Choudongning capsule (CDN)in children with Tourette's syndrome of spleen deficiency and phlegm accumulation. Zhongguo Zhong Yao Za Zhi. 2016;41(16):3100-6. https:// doi.org/10.4268/cjcmm20161627.

116. Zheng Y, Zhang ZJ, Han XM, Ding Y, Chen YY, Wang XF, et al. A proprietary herbal medicine (5-Ling Granule) for Tourette syndrome: a randomized controlled trial. J Child Psychol Psychiatry. 2016;57(1):74-83. https://doi.org/10.1111/jcpp.12432.

117. Hu S, Ma R, TIan T. Phase III clinical research of Changma Xifeng tablets in treating multiple tics with liver wind and sputum stirring internally (in Chinese). Drugs Clin. 2014;29(9):1044-9. 
118. Sun Q. Clinical observation on Changma Xifeng tablets in the treatment of 36 cases of Tourette's syndrome. Management of Health Standards in China. 2016;131(2):1674-93.

119. Lu C, Wu LQ, Hao H, Kimberly Leow X, Xu FW, Li PP, et al. Clinical efficacy and safety of acupuncture treatment of TIC disorder in children: a systematic review and meta-analysis of 22 randomized controlled trials. Complement Ther Med. 2021;59: 102734. https://doi.org/10.1016/j.ctim.2021.102734.

120. Yu J, Ye Y, Liu J, Wang Y, Peng W, Liu Z. Acupuncture for Tourette syndrome: a systematic review. Evid Based Complement Alternat Med. 2016;2016:1834646. https://doi.org/10.1155/ 2016/1834646.

121. Chung S, Noh B, Lee C, Hwang M, Kang M, Kwon S, et al. Acupuncture for Tourette syndrome: a systematic review and meta-analysis. Eur J Integ Med. 2016;8:809-16.

122. Ding L, Yang Z, Liu G, Ran N, Yi M, Li H, et al. Safety and efficacy of taurine as an add-on treatment for tics in youngsters. Eur J Neurol. 2020;27(3):490-7. https://doi.org/10.1111/ene. 14107.

123. Bond M, Moll N, Rosello A, Bond R, Schnell J, Burger B, et al. Vitamin D levels in children and adolescents with chronic tic disorders: a multicentre study. Eur Child Adolesc Psychiatry. 2021. https://doi.org/10.1007/s00787-021-01757-y.

124. Li HH, Shan L, Wang B, Du L, Xu ZD, Jia FY. Serum 25-hyroxyvitamin D levels and tic severity in Chinese children with tic disorders. Psychiatry Res. 2018;267:80-4. https://doi.org/10. 1016/j.psychres.2018.05.066.

125. Li HH, Xu ZD, Wang B, Feng JY, Dong HY, Jia FY. Clinical improvement following vitamin D3 supplementation in children with chronic tic disorders. Neuropsychiatr Dis Treat. 2019;15:2443-50. https://doi.org/10.2147/NDT.S212322.

126. Murakami J, Tachibana Y, Akiyama S, Kato T, Taniguchi A, Nakajima Y, et al. Oral splint ameliorates tic symptoms in patients with Tourette syndrome. Mov Disord. 2019;34(10):1577-8. https://doi.org/10.1002/mds.27819.

127. Liu YW, Liong MT, Chung YE, Huang HY, Peng WS, Cheng YF et al. Effects of nutrients. 2019;11(4). doi:https://doi.org/10. 3390/nu11040820.

128. Zhao H, Shi Y, Luo X, Peng L, Yang Y, Zou L. The effect of fecal microbiota transplantation on a child with Tourette syndrome. Case Rep Med. 2017;2017:6165239. https://doi.org/10. $1155 / 2017 / 6165239$.

129. Zhao HJ, Luo X, Shi YC, Li JF, Pan F, Ren RR, et al. The efficacy of fecal microbiota transplantation for children with Tourette syndrome: a preliminary study. Front Psychiatry. 2020;11: 554441. https://doi.org/10.3389/fpsyt.2020.554441.

130. McGuire JF, Ginder N, Ramsey K, Essoe JK, Ricketts EJ, McCracken JT, et al. Optimizing behavior therapy for youth with Tourette's disorder. Neuropsychopharmacology. 2020;45(12):2114-9. https://doi.org/10.1038/ s41386-020-0762-4.

131. Fletcher J, Martino D, Pringsheim T. Novel pharmacological approaches for Tourette syndrome. Curr Dev Disord Rep. 2020;7:270-6.

132. Chae JH, Nahas Z, Wassermann E, Li X, Sethuraman G, Gilbert $\mathrm{D}$, et al. A pilot safety study of repetitive transcranial magnetic stimulation (rTMS) in Tourette's syndrome. Cogn Behav Neurol. 2004;17(2):109-17. https://doi.org/10.1097/01.wnn.00001 $16253.78804 .3 \mathrm{a}$

133. Kahl CK, Kirton A, Pringsheim T, Croarkin PE, Zewdie E, Swansburg R, et al. Bilateral transcranial magnetic stimulation of the supplementary motor area in children with Tourette syndrome. Dev Med Child Neurol. 2021;63(7):808-15. https://doi. org/10.1111/dmcn.14828.

134. Kwon HJ, Lim WS, Lim MH, Lee SJ, Hyun JK, Chae JH, et al. $1-\mathrm{Hz}$ low frequency repetitive transcranial magnetic stimulation in children with Tourette's syndrome. Neurosci Lett. 2011;492(1):1-4. https://doi.org/10.1016/j.neulet.2011.01.007.

135. Landeros-Weisenberger A, Mantovani A, Motlagh MG, de Alvarenga PG, Katsovich L, Leckman JF, et al. Randomized sham controlled double-blind trial of repetitive transcranial magnetic stimulation for adults with severe Tourette syndrome. Brain Stimul. 2015;8(3):574-81. https://doi.org/10.1016/j.brs.2014. 11.015

136. Le K, Liu L, Sun M, Hu L, Xiao N. Transcranial magnetic stimulation at 1 Hertz improves clinical symptoms in children with Tourette syndrome for at least 6 months. J Clin Neurosci. 2013;20(2):257-62. https://doi.org/10.1016/j.jocn.2012.01.049.

137. Mantovani A, Lisanby SH, Pieraccini F, Ulivelli M, Castrogiovanni P, Rossi S. Repetitive transcranial magnetic stimulation (rTMS) in the treatment of obsessive-compulsive disorder (OCD) and Tourette's syndrome (TS). Int J Neuropsychopharmacol. 2006;9(1):95-100. https://doi.org/10.1017/S146114570 5005729.

138. Mantovani A, Leckman JF, Grantz H, King RA, Sporn AL, Lisanby SH. Repetitive transcranial magnetic stimulation of the supplementary motor area in the treatment of Tourette syndrome: report of two cases. Clin Neurophysiol. 2007;118(10):2314-5. https://doi.org/10.1016/j.clinph.2007.07.011.

139. Münchau A, Bloem BR, Thilo KV, Trimble MR, Rothwell JC, Robertson MM. Repetitive transcranial magnetic stimulation for Tourette syndrome. Neurology. 2002;59(11):1789-91. https:// doi.org/10.1212/01.wnl.0000036615.25044.50.

140. Orth M, Kirby R, Richardson MP, Snijders AH, Rothwell JC, Trimble MR, et al. Subthreshold rTMS over pre-motor cortex has no effect on tics in patients with Gilles de la Tourette syndrome. Clin Neurophysiol. 2005;116(4):764-8. https://doi.org/ 10.1016/j.clinph.2004.10.003.

141. Wu SW, Maloney T, Gilbert DL, Dixon SG, Horn PS, Huddleston DA, et al. Functional MRI-navigated repetitive transcranial magnetic stimulation over supplementary motor area in chronic tic disorders. Brain Stimul. 2014;7(2):212-8. https://doi.org/10. 1016/j.brs.2013.10.005.

142. Fu M, Wei H, Meng X, Chen H, Shang B, Chen F, et al. Effects of low-frequency repetitive transcranial magnetic stimulation of the bilateral parietal cortex in patients with Tourette syndrome. Front Neurol. 2021;12: 602830. https://doi.org/10.3389/fneur. 2021.602830.

143. Motiwala F, Sangroula D, Ashraf S, Virk I. Repetitive transcranial magnetic stimulation for tic disorders. Curr Psych. 2018;17(6):24-5.

144. Hsu CW, Wang LJ, Lin PY. Efficacy of repetitive transcranial magnetic stimulation for Tourette syndrome: a systematic review and meta-analysis. Brain Stimul. 2018;11(5):1110-8. https://doi. org/10.1016/j.brs.2018.06.002.

145. Bloch Y, Arad S, Levkovitz Y. Deep TMS add-on treatment for intractable Tourette syndrome: a feasibility study. World J Biol Psychiatry. 2016;17(7):557-61. https://doi.org/10.3109/15622 975.2014.964767.

146. Singh S, Kumar S, Kumar N, Verma R. Low-frequency repetitive transcranial magnetic stimulation for treatment of tourette syndrome: a naturalistic study with 3 months of follow-up. Indian J Psychol Med. 2018;40(5):482-6. https://doi.org/10.4103/IJPSYM.IJPSYM_332_17.

147. Eapen V, Baker R, Walter A, Raghupathy V, Wehrman JJ, Sowman PF. The role of transcranial direct current stimulation (tDCS) in Tourette syndrome: a review and preliminary findings. Brain Sci. 2017;7(12). doi:https://doi.org/10.3390/brain sci7120161.

148. Dyke K, Jackson GM, Nixon E, Jackson SR. Effects of single-session cathodal transcranial direct current stimulation on tic symptoms in Tourette's syndrome. Exp Brain 
Res. 2019;237(11):2853-63. https://doi.org/10.1007/ s00221-019-05637-5.

149. Martino D, Nosratmishekarlou E, Jasaui Y, Medina A, Vicario $\mathrm{C}$, Nitsche $\mathrm{M}$ et al. Transcranial direct current stimulation over the supplementary motor area in Tourette syndrome: preliminary findings of a randomized controlled trial. Mov Disord. 2020;35.

150. Mrakic-Sposta S, Marceglia S, Mameli F, Dilena R, Tadini L, Priori A. Transcranial direct current stimulation in two patients with Tourette syndrome. Mov Disord. 2008;23(15):2259-61. https://doi.org/10.1002/mds.22292.

151. Tajadini S, Mohammadi N, Tahamtan M, Nami M. Cathodal transcranial direct current stimulation to ameliorate the frequency and severity of motor tics: a case study of Tourette syndrome. JAMSAT. 2018;4(1):21-6.

152. Carvalho S, Gonçalves Ó, Soares JM, Sampaio A, Macedo F, Fregni F, et al. Sustained effects of a neural-based intervention in a refractory case of Tourette syndrome. Brain Stimul. 2015;8(3):657-9. https://doi.org/10.1016/j.brs.2014.12.008.

153. Behler N, Leitner B, Mezger E, Weidinger E, Musil R, Blum $\mathrm{B}$, et al. Cathodal tDCS over motor cortex does not improve Tourette syndrome: lessons learned from a case series. Front Behav Neurosci. 2018;12:194. https://doi.org/10.3389/fnbeh. 2018.00194.

154. Diamond A, Kenney C, Jankovic J. Effect of vagal nerve stimulation in a case of Tourette's syndrome and complex partial epilepsy. Mov Disord. 2006;21(8):1273-5. https://doi.org/10.1002/ mds.20949.

155. Sperling W, Reulbach U, Maihöfner C, Kornhuber J, Bleich $\mathrm{S}$. Vagus nerve stimulation in a patient with Gilles de la Tourette syndrome and major depression. Pharmacopsychiatry. 2008;41(3):117-8. https://doi.org/10.1055/s-2008-1062698.

156. Caffery C. Transcutaneous vagal nerve stimulation \& breathing exercises reduce motor and vocal tics in eleven-year-old male. Front Neurol. 2018.

157. Münchau A, Colzato LS, AghajaniAfjedi A, Beste C. A neural noise account of Gilles de la Tourette syndrome. Neuroimage Clin. 2021;30: 102654. https://doi.org/10.1016/j.nicl.2021. 102654.

158. Morera Maiquez B, Sigurdsson HP, Dyke K, Clarke E, McGrath $\mathrm{P}$, Pasche M, et al. Entraining movement-related brain oscillations to suppress tics in Tourette syndrome. Curr Biol. 2020;30(12):2334-42.e3. https://doi.org/10.1016/j.cub.2020. 04.044 .

159. Morera Maiquez B, Jackson GM, Jackson SR. Examining the neural antecedents of tics in Tourette syndrome using electroencephalography. J Neuropsychol. 2021. https://doi.org/10.1111/ jnp.12245.

160. Qiao J, Weng S, Wang P, Long J, Wang Z. Normalization of intrinsic neural circuits governing Tourette's syndrome using cranial electrotherapy stimulation. IEEE Trans Biomed Eng. 2015;62(5):127280. https://doi.org/10.1109/TBME.2014.2385151.

161. Deeb W, Leentjens AFG, Mogilner AY, Servello D, Meng F, Zhang J, et al. Deep brain stimulation lead removal in Tourette syndrome. Parkinsonism Relat Disord. 2020;77:89-93. https:// doi.org/10.1016/j.parkreldis.2020.06.025.

162. Schrock LE, Mink JW, Woods DW, Porta M, Servello D, Visser-Vandewalle $\mathrm{V}$ et al. Tourette syndrome deep brain stimulation: a review and updated recommendations. Mov Disord. 2015;30(4):448-71. doi:https://doi.org/10.1002/mds.26094.

163.•• Martino D, Deeb W, Jimenez-Shahed J, Malaty I, Pringsheim TM, Fasano A, et al. The 5 pillars in Tourette syndrome deep brain stimulation patient selection: present and future. Neurology. 2021;96(14):664-76. https://doi.org/10.1212/WNL.00000 00000011704. Important guideline updates for how to select patients with TS for DBS treatment
164. Deeb W, Malaty I. Deep brain stimulation for Tourette syndrome: potential role in the pediatric population. J Child Neurol. 2020;35(2):155-65. https://doi.org/10.1177/0883073819872620.

165. Hauseux PA, Cyprien F, Cif L, Gonzalez V, Boulenger JP, Coubes $\mathrm{P}$ et al. Long-term follow-up of pallidal deep brain stimulation in teenagers with refractory Tourette syndrome and comorbid psychiatric disorders: about three cases. Eur J Paediatr Neurol. 2017;21(1):214-7. doi:https://doi.org/10.1016/j.ejpn. 2016.06.005.

166. Coulombe MA, Elkaim LM, Alotaibi NM, Gorman DA, Weil AG, Fallah A, et al. Deep brain stimulation for Gilles de la Tourette syndrome in children and youth: a meta-analysis with individual participant data. J Neurosurg Pediatr. 2018;23(2):236-46. https://doi.org/10.3171/2018.7.PEDS18300. Good overview of the safety and efficacy of DBS for TS

167. Casagrande SCB, Cury RG, Alho EJL, Fonoff ET. Deep brain stimulation in Tourette's syndrome: evidence to date. Neuropsychiatr Dis Treat. 2019;15:1061-75. https://doi.org/10.2147/NDT. S139368.

168. Deeb W, Rossi PJ, Porta M, Visser-Vandewalle V, Servello D, Silburn P, et al. The International Deep Brain Stimulation Registry and Database for Gilles de la Tourette Syndrome: how does it work? Front Neurosci. 2016;10:170. https://doi.org/10.3389/ fnins.2016.00170.

169. Akbarian-Tefaghi L, Zrinzo L, Foltynie T. The use of deep brain stimulation in Tourette syndrome. Brain Sci. 2016;6(3). doi:https://doi.org/10.3390/brainsci6030035.

170. Xu W, Zhang C, Deeb W, Patel B, Wu Y, Voon V, et al. Deep brain stimulation for Tourette's syndrome. Transl Neurodegener. 2020;9:4. https://doi.org/10.1186/s40035-020-0183-7.

171. Servello D, Galbiati TF, Balestrino R, Iess G, Zekaj E, Michele S et al. Deep brain stimulation for Gilles de la Tourette syndrome: toward limbic targets. Brain Sci. 2020;10(5). doi:https://doi.org/ 10.3390/brainsci10050301

172. Baldermann JC, Schüller T, Huys D, Becker I, Timmermann L, Jessen F, et al. Deep brain stimulation for Tourette-syndrome: a systematic review and meta-analysis. Brain Stimul. 2016;9(2):296-304. https://doi.org/10.1016/j.brs.2015.11.005.

173. Huys D, Bartsch C, Koester P, Lenartz D, Maarouf M, Daumann J, et al. Motor improvement and emotional stabilization in patients with Tourette syndrome after deep brain stimulation of the ventral anterior and ventrolateral motor part of the thalamus. Biol Psychiatry. 2016;79(5):392-401. https://doi.org/10.1016/j. biopsych.2014.05.014.

174. Rossi PJ, Opri E, Shute JB, Molina R, Bowers D, Ward H, et al. Scheduled, intermittent stimulation of the thalamus reduces tics in Tourette syndrome. Parkinsonism Relat Disord. 2016;29:3541. https://doi.org/10.1016/j.parkreldis.2016.05.033.

175. Schoenberg MR, Maddux BN, Riley DE, Whitney CM, Ogrocki PK, Gould D, et al. Five-months-postoperative neuropsychological outcome from a pilot prospective randomized clinical trial of thalamic deep brain stimulation for Tourette syndrome. Neuromodulation. 2015;18(2):97-104. https://doi.org/10.1111/ ner. 12233 .

176. Servello D, Zekaj E, Saleh C, Lange N, Porta M. Deep brain stimulation in Gilles de la Tourette syndrome: what does the future hold? A cohort of 48 patients. Neurosurgery. 2016;78(1):91-100. https://doi.org/10.1227/NEU.0000000000 001004.

177. Okun MS, Foote KD, Wu SS, Ward HE, Bowers D, Rodriguez $\mathrm{RL}$, et al. A trial of scheduled deep brain stimulation for Tourette syndrome: moving away from continuous deep brain stimulation paradigms. JAMA Neurol. 2013;70(1):85-94. https://doi.org/10. 1001/jamaneurol.2013.580.

178. Ackermans L, Duits A, van der Linden C, Tijssen M, Schruers K, Temel Y, et al. Double-blind clinical trial of thalamic stimulation 
in patients with Tourette syndrome. Brain. 2011;134(Pt 3):83244. https://doi.org/10.1093/brain/awq380.

179. Kefalopoulou Z, Zrinzo L, Jahanshahi M, Candelario J, Milabo $\mathrm{C}$, Beigi M, et al. Bilateral globus pallidus stimulation for severe Tourette's syndrome: a double-blind, randomised crossover trial. Lancet Neurol. 2015;14(6):595-605. https://doi.org/10.1016/ S1474-4422(15)00008-3.

180. Welter ML, Houeto JL, Thobois S, Bataille B, Guenot M, Worbe $\mathrm{Y}$, et al. Anterior pallidal deep brain stimulation for Tourette's syndrome: a randomised, double-blind, controlled trial. Lancet Neurol. 2017;16(8):610-9. https://doi.org/10.1016/S1474-4422(17)30160-6.

181. Baldermann JC, Kuhn J, Schüller T, Kohl S, Andrade P, Schleyken S, et al. Thalamic deep brain stimulation for Tourette syndrome: a naturalistic trial with brief randomized, double-blinded sham-controlled periods. Brain Stimul. 2021;14(5):1059-67. https://doi.org/10.1016/j.brs.2021.07.003.

182. Welter ML, Mallet L, Houeto JL, Karachi C, Czernecki V, Cornu $\mathrm{P}$, et al. Internal pallidal and thalamic stimulation in patients with Tourette syndrome. Arch Neurol. 2008;65(7):952-7. https://doi.org/10.1001/archneur.65.7.952.

183. Marceglia S, Rosa M, Servello D, Porta M, Barbieri S, Moro E et al. Adaptive deep brain stimulation (aDBS) for Tourette syndrome. Brain Sci. 2017;8(1). doi:https://doi.org/10.3390/brain sci8010004.

184. Neumann WJ, Huebl J, Brücke C, Lofredi R, Horn A, Saryyeva $\mathrm{A}$, et al. Pallidal and thalamic neural oscillatory patterns in Tourette's syndrome. Ann Neurol. 2018;84(4):505-14. https://doi. org/10.1002/ana.25311

185. Molina R, Okun MS, Shute JB, Opri E, Rossi PJ, Martinez-Ramirez D, et al. Report of a patient undergoing chronic responsive deep brain stimulation for Tourette syndrome: proof of concept. J Neurosurg. 2018;129(2):308-14. https://doi.org/10.3171/2017.6. JNS17626.

Publisher's Note Springer Nature remains neutral with regard to jurisdictional claims in published maps and institutional affiliations. 